\title{
Cor, Educação e Casamento: Tendências da Seletividade Marital no Brasil, 1960 a 2000*
}

\author{
Carlos Antonio Costa Ribeiro \\ Nelson do Valle Silva
}

\section{INTRODUÇÃO}

E studos sobre casamentos inter-raciais no Brasil têm indicado que os indivíduos autoidentificados como pardos têm chances maiores de se casar com brancos do que com pretos. Ou seja, no mercado matrimonial, pardos se encontram relativamente mais próximos de brancos, e os pretos parecem estar mais isolados se comparados a esses dois outros grupos (Silva, 1987). Esses resultados sugerem que as distâncias separando brancos, pardos e pretos, no mercado matrimonial, não seriam equivalentes às distâncias mais estritamente socioeconômicas entre os grupos de cor, ou raciais, uma vez que essas desigualdades no sistema educacional e no mercado de trabalho indicam claramente que pardos estão bem mais próximos de pretos e que ambos os grupos estão em clara desvantagem em relação aos brancos. Além disso, utilizando dados de 1980, os estudos sobre o mercado matrimonial preveem um crescente aumento dos casamentos inter-raciais (ibidem; 1992). Esses padrões de casamento inter-racial favorecem o aumento da miscigenação e sugerem que as relações raciais no Brasil se caracterizam por uma crescente fluidez ou abertura à aceitação dos

\footnotetext{
* Carlos Antonio Costa Ribeiro agradece o apoio do Center for Advanced Study in the Behavioral Sciences at Stanford University, onde este artigo foi concebido e escrito.

DADOS - Revista de Ciências Sociais, Rio de Janeiro, Vol. 52, nํ1, 2009, pp. 7 a 51.
} 
diferentes grupos de cor na esfera dos relacionamentos sociais ou de sociabilidade.

Os dados que analisamos no presente artigo confirmam a indicação de que há um aumento dos casamentos inter-raciais no Brasil e, portanto, um provável aumento gradativo da miscigenação ao longo do último meio século. Em 1960, 1 em cada 10 de todos os casamentos era entre pessoas de grupos de cor diferentes; em 1980, esse número aumentou para 1 em cada 5; em 2000, para 1 em cada 3. Por outro lado, também sabemos que, nesse mesmo período, entre 1960 e 2000, o Brasil se transformou radicalmente em termos de estrutura social. Deixou de ser um país predominantemente rural para se tornar uma nação altamente industrializada, expandiu o acesso à educação em todos os níveis, modernizou-se de maneira rápida e definitiva. Acompanhando essa modernização, paralelamente ao aumento dos casamentos inter-raciais, ocorreram duas outras mudanças que podem a ele estar relacionadas. Por um lado, houve uma diminuição das barreiras educacionais aos casamentos (Silva, 2003), ou seja, o percentual de casamentos entre maridos e esposas com níveis educacionais distintos aumentou ao longo dessas quatro décadas. Em 1960, somente 20,8\% dos casamentos eram entre maridos e esposas com níveis educacionais distintos, ao passo que, em 1980, esse percentual aumentou para 40,6\% e, em 2000, para $51,9 \%$. Somando-se a esse aumento de casamentos intereducacionais, verifica-se um crescimento do acesso ao sistema educacional, bem como uma progressão relativa de pretos e pardos, levando a uma diminuição proporcional das desigualdades educacionais entre os grupos de cor. Enquanto em 1960 os brancos tinham em média 2,2 anos a mais de educação do que os pardos (com diferença muito semelhante entre brancos e pretos), em 2000 essa diferença se reduzia para 1,2 ano a mais. Em outras palavras, a desigualdade educacional entre brancos e não brancos diminuiu consideravelmente.

Uma hipótese que pode ser interessante seria aquela propondo que a diminuição das barreiras educacionais ao casamento e das desigualdades educacionais entre os grupos de cor pode estar relacionada ao aumento dos casamentos inter-raciais, hipótese esta que, como vimos, foi prevista nos estudos anteriores e confirmada pelos dados analisados no presente artigo. Nosso objetivo aqui será investigar a relação entre essas três tendências observadas no Brasil nas últimas décadas. Tentaremos responder às seguintes perguntas: em que medida diminuíram as barreiras ao casamento inter-racial e intereducacional entre 1960 e 
2000? Qual é a relação entre esses dois tipos de barreira? Será que a diminuição das barreiras ao casamento inter-racial pode ser explicada, em parte, pela diminuição das barreiras ao casamento intereducacional? Será que pode ser explicada pela diminuição das desigualdades educacionais entre os grupos raciais?

Para responder a essas perguntas, utilizamos amostras dos censos populacionais de 1960, 1980 e 2000. Estudos anteriores sobre casamento inter-racial se concentraram nos anos específicos de 1980 ou 1991 e só analisaram as tendências de longa duração utilizando informações sobre coortes de idade (Silva, 1992; Telles, 2004). Já os estudos sobre barreiras educacionais ao casamento analisaram as tendências históricas, nas décadas de 1980 e 1990, utilizando dados de 1981, 1990 e 1999. Nenhum desses estudos, no entanto, combinou a análise das mudanças nas barreiras raciais e educacionais com os casamentos. Ao analisarmos conjuntamente a mudança nos dois tipos de barreira entre 1960 e 2000 , seremos capazes de verificar em que medida a diminuição das barreiras ao casamento inter-racial é um reflexo da diminuição das barreiras educacionais ao casamento e da desigualdade educacional entre os grupos de cor.

Com o objetivo de investigar essas questões, dividimos este artigo em nove partes. A primeira é esta introdução. Na segunda, apresentamos o debate teórico sobre seletividade matrimonial; na terceira, a literatura sobre seletividade matrimonial no Brasil. Na quarta parte, descrevemos os dados e modelos utilizados. Na quinta, analisamos as taxas absolutas de casamento por cor e educação. Na sexta e na sétima, mostramos o ajuste dos modelos utilizados para analisar a seletividade matrimonial por cor e educação, respectivamente. Na oitava parte, analisamos conjuntamente (em um mesmo modelo) a seletividade matrimonial por cor e educação. A última parte se debruça sobre as conclusões que podemos tirar das análises feitas.

\section{TEORIAS SOBRE SELETIVIDADE MARITAL}

Um tema que tem uma longa tradição dentro das ciências sociais é o da escolha conjugal, ou, em outro termo também usual, a seletividade marital. Nesse caso, tenta-se explicar a tendência empírica e universalmente observada que as pessoas têm em escolher seu cônjuge, seja dentro de seu próprio grupo social, a chamada endogamia (por oposição ao casamento fora do grupo, a exogamia), seja entre aqueles com situação 
social semelhante, a denominada homogamia (por oposição ao casamento socialmente desigual, a heterogamia). Assim, o estudo da seletividade marital diz respeito à análise da relação entre as características sociais dos esposos, bem como de suas consequências para a dinâmica da vida social. Esse tema tem sido estudado em grande diversidade de contextos sociais e nacionais (Murstein, 1976; Bozon e Héran,1989; Forsé e Chauvel, 1995; Smits, Ultee e Lammers, 1998), dando origem a uma produção bibliográfica bastante extensa, que foi objeto de uma útil revisão por Kalmijn (1998).

Uma grande parte, se não a maioria dos estudos sociológicos sobre padrões de casamento entre diferentes grupos sociais, tem dois objetivos principais: por um lado, delinear as "fronteiras" que separam esses grupos; por outro, estudar as consequências dos padrões de intercasamento para as gerações futuras. Pelo menos desde os trabalhos de Weber (1978) sobre fechamento dos grupos de status e criação de grupos étnicos, estudiosos vêm considerando o padrão de casamentos um indicador das fronteiras mediando a relação entre grupos sociais distintos. Sobre grupos étnicos, por exemplo, Weber afirma claramente que: "Em todos os grupos com uma consciência 'étnica' desenvolvida, a existência ou ausência de intercasamentos (connubium) seria uma consequência normal da atração ou segregação racial" (ibidem:385; tradução dos autores). Tendo em vista que o casamento é, em geral, uma forma de relacionamento íntimo e duradouro, os padrões de intercasamento - raciais, nacionais, religiosos, socioeconômicos etc. - podem ser usados como uma medida tanto das barreiras que separam os grupos quanto da aceitação mútua entre os membros desses grupos. A heterogamia, ou intercasamento, pode ser entendida como uma forma de relação "íntima" entre grupos distintos; inversamente, a endogamia, ou homogamia, pode ser vista como indicador do grau de fechamento dos grupos sociais. Não são apenas as fronteiras entre grupos sociais que se revelam nos padrões de intercasamento, mas também as possibilidades de mudança nessas barreiras. Se houver índices altos de heterogamia, ou exogamia, em uma determinada sociedade, os filhos de casamentos mistos terão maior liberdade para se identificar com mais de um grupo, o que significa que uma maior miscigenação ou mistura dos grupos se tornará mais provável.

Embora os padrões de intercasamento possam ser usados para definir fronteiras e formas de aceitação entre grupos sociais, como sugeria Weber, os estudiosos contemporâneos do tema propõem algumas es- 
pecificações teóricas e metodológicas importantes na tentativa de explicar os mecanismos que levam aos padrões observados. Em particular, a literatura parte da ideia de que as taxas de endogamia e exogamia observadas em qualquer sociedade são o produto de forças sociais relacionadas a: (1) preferências e vontades individuais; (2) influências dos grupos ou normas sociais; e (3) características estruturais dos mercados matrimoniais. Estudos sobre intercasamento devem elaborar modelos que especifiquem e mensurem explícita ou implicitamente essas três forças sociais. Na prática, a diferenciação metodológica entre variáveis relacionadas às preferências individuais e às influências dos grupos sociais (ou normas sociais) é difícil de ser feita em modelos estatísticos usando dados empíricos.

Para organizar os conceitos envolvidos na discussão da seletividade por cor no casamento, podemos partir de uma representação gráfica (Figura 1), proposta por Silva (1987), com base nos estudos de Bumpass (1970) e Johnson (1980).

Nos modelos estatísticos que elaboramos mais adiante, levamos em conta os seguintes fatores representados no esquema analítico abaixo: (b) similaridade socioeconômica e/ou educacional; (d) mercados locais (no caso, a escola); (e) composição populacional; (f) normas endo-

Figura 1

Esquema Conceitual da Análise da Seletividade Conjugal

(1) Preferências individuais:

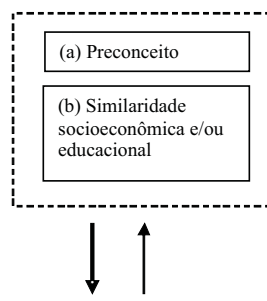

(3) Características estruturais:
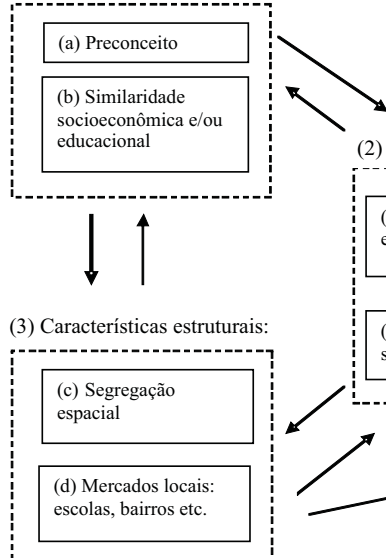

(2)

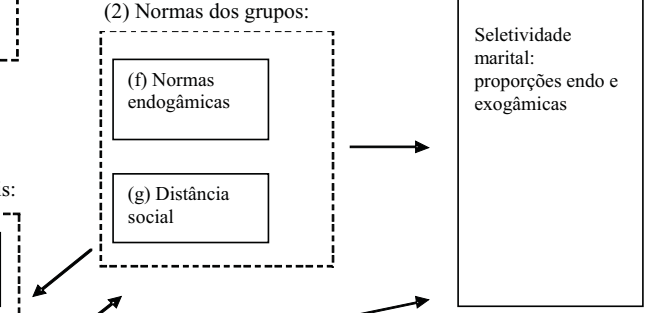

(e) Composição

populacional

Elaboração dos autores. 
gâmicas; e (g) distância social. Na prática, é difícil distinguir (b) de (f) e (b) de (g), ou seja, é difícil verificar se são preferências individuais ou normas do grupo que influenciam os padrões de seletividade marital. Em contraste, os modelos log-lineares que utilizamos são adequados para distinguir as influências da composição populacional (e), das normas endogâmicas (f) e da distância social (g). Embora não tenhamos informações sobre os mercados locais, alguns autores sugerem que a homogamia educacional entre pessoas com algum nível universitário seria um reflexo do fato de a universidade ser um mercado local de casamento (Mare, 1991). Nesse sentido, também seria difícil, metodologicamente, distinguir as normas endogâmicas (f), em termos educacionais (principalmente entre universitários), do mercado local (d) representado pelas universidades. Outra limitação do modelo que utilizamos é o fato de não incluirmos características da segregação espacial (c). O efeito do preconceito (a) também será apenas presumido no modelo, na medida em que podemos imaginar que as normas endogâmicas (f) e a distância social (g) estão relacionadas não apenas às similaridades socioeconômicas (b) mas também ao preconceito (a). Apesar dessas limitações, cremos que o esquema anterior (Figura 1) ajuda a organizar os conceitos e teorias utilizados nos estudos sobre seletividade marital. Em certa medida, todas as teorias sobre padrões de intercasamento levam em conta esses três aspectos que conformam os padrões observados. Não obstante, podemos, grosso modo, identificar teorias que dão maior ênfase a apenas um desses aspectos.

O economista Gary Becker (1981), por exemplo, afirma que os indivíduos preferem e competem por parceiros que tenham características socioeconômicas valorizadas. Essas preferências, ou a maximização delas, seriam a principal força moldando os padrões de casamento observados. Por exemplo, as pessoas maximizam sua renda na medida em que procuram e encontram parceiros com recursos socioeconômicos atrativos. As competições por recursos socioeconômicos no mercado matrimonial poderiam ser investigadas a partir da associação estatística entre as características dos cônjuges, que por sua vez levam a padrões agregados de homogamia. Além disso, Becker afirma que a natureza da competição, no mercado matrimonial, variaria de acordo com o papel desempenhado pelas mulheres na sociedade. Por exemplo, em sociedades em que há uma forte divisão sexual entre trabalho pago e doméstico, os homens procurariam se casar com mulheres que desempenhem bem o trabalho doméstico e de procriação, e as mulheres procurariam homens com capacidade de produzir mais renda. 
Argumentos semelhantes foram propostos para a troca de prestígio e status no mercado matrimonial, ou seja, quando o status ou prestígio depende do trabalho do homem, haveria uma troca por outros aspectos valorizados das mulheres, como beleza, origem de classe ou sofisticação cultural (Jacobs e Furstenberg Jr., 1986). Tanto as trocas econômicas quanto as de prestígio ou status vêm passando por enormes modificações na medida em que as mulheres estão participando cada vez mais do mercado de trabalho. Essa mudança estaria levando a uma tendência crescente a valorização dos recursos propriamente socioeconômicos das mulheres nos mercados matrimoniais (Davis, 1984).

Em contraste com essas teorias enfatizando a competição no mercado matrimonial, alguns autores sugerem que as pessoas tendem a se casar com pessoas com as quais compartilhem valores e visões de mundo. Dessa forma, semelhanças culturais favoreceriam a atração entre as pessoas, facilitariam a convivência e contribuiriam para o entendimento mútuo (DiMaggio e Mohr, 1985; Kalmijn, 1994). Na prática, a partir de análises empíricas, é muito difícil definir se as pessoas escolhem seus parceiros em uma competição no mercado matrimonial ou em um processo de procura por pessoas culturalmente semelhantes.

Tendo em vista essa dificuldade metodológica, alguns autores argumentam que diversas características sociais estão correlacionadas a recursos socioeconômicos e que, portanto, a homogamia, ou endogamia, em termos de algumas características sociais, seria na realidade uma consequência indireta (ou by-product) desse tipo de correlação (Kalmijn, 1991a). Segundo Murstein (1976), o processo social para se encontrar um parceiro tem duas etapas. Em um primeiro momento, as pessoas criam círculos de amigos, conhecidos e possíveis candidatos ao casamento, com os quais compartilham certas características sociais em comum. Em um segundo momento, as pessoas encontram seus parceiros por meio da interação nesses círculos sociais relativamente homogêneos em termos de características sociais, econômicas e culturais. Por causa desse tipo de processo, seria comum encontrarmos uma forte correlação entre diferentes características dos cônjuges.

Por exemplo, como renda ou educação estão correlacionadas aos grupos de cor no Brasil, poderíamos supor que a homogamia racial é, na realidade, uma consequência indireta da convivência dos indivíduos com outros tendo recursos socioeconômicos semelhantes. Essa última perspectiva é relevante para nossas análises neste artigo, uma vez que 
investigamos em que medida os padrões de casamento inter-racial no Brasil estão relacionados (ou são um by-product) aos padrões de seletividade matrimonial por nível educacional dos cônjuges. Nossas análises permitem distinguir esses dois efeitos.

Além das preferências individuais, há normas (influências) dos grupos e fatores demográficos que podem estar relacionados aos padrões de casamento. Ao teorizar sobre casamentos inter-raciais nos Estados Unidos, Merton (1941) argumenta que normas de endogamia seriam muito fortes para os diferentes grupos étnicos. Outros autores enfatizam que a expansão educacional levaria os indivíduos a se tornarem mais independentes em relação às normas de seus grupos de origem, $\mathrm{o}$ que implicaria um aumento dos casamentos entre grupos raciais ou com origens de classe distintas (Qian, 1997). Valores particularistas relacionados aos grupos de origem seriam substituídos por valores universalistas ligados à sociedade moderna, em que as pessoas tendem a ter mais educação (Smits, Ultee e Lammers, 1998). Mais uma vez há dificuldades metodológicas para distinguir preferências individuais de normas dos grupos, uma vez que os estudos empíricos estão, na realidade, apenas analisando a associação estatística entre características dos cônjuges. Por exemplo, se a associação entre cor de maridos e de esposas estiver diminuindo ao longo do tempo, não temos como decidir se foi por causa de mudanças nas preferências dos indivíduos (o preconceito estaria diminuindo) ou nas normas de endo(homo)gamia impostas pelas famílias brancas, pardas e pretas. Poderíamos mesmo argumentar que, no mundo social, ambas estão relacionadas.

De qualquer forma, o modelo que elaboramos mais adiante permite controlar a associação entre cor de maridos e de esposas por seus respectivos níveis educacionais. Podemos, portanto, testar se a distância entre os grupos de cor está relacionada (é um by-product) às distâncias educacionais entre cônjuges. A ideia weberiana de que os padrões de casamento são medidas adequadas das fronteiras entre grupos sociais e de status pode ser perseguida a partir dos modelos que apresentamos, mas não podemos decidir se são preferências individuais ou normas sociais que conformam esses padrões. Apesar dessas limitações, os modelos que utilizamos são adequados para separar o efeito da composição populacional (e) do efeito da associação estatística entre características de cônjuges, que poderia ser tanto um fruto das preferências individuais (1) quanto das normas dos grupos (2) ou de uma 
combinação entre ambas - (1) e (2) -, tal como representado no esquema da Figura 1.

Em um importante estudo sobre círculos sociais, Blau e Schwartz (1984) propuseram uma teoria estrutural sobre os casamentos que aponta para a importância de aspectos demográficos, relativos ao tamanho dos grupos, e geográficos, relativos à distribuição espacial dos grupos. Do ponto de vista demográfico, a endogamia está negativamente relacionada ao grau de heterogeneidade da população. Para explicar essa tendência, Blau e Schwartz nos dão o exemplo de duas populações hipotéticas constituídas cada uma por dois grupos sociais. A primeira população é heterogênea, tendo $50 \%$ em cada grupo social (por exemplo, 100 no grupo A e 100 no B), enquanto a segunda é relativamente homogênea, tendo $90 \%$ em um grupo e $10 \%$ no outro (por exemplo, 180 no grupo A e 20 no B). Ambas as populações têm número igual de homens e mulheres. Na população heterogênea, o número de mulheres casando com homens do mesmo grupo é $0,5 \times 50=25$ para Ae $0,5 \times 50=25$ para B, ou seja, $50 \%$ dos casamentos seriam endogâmicos. Em contraste, na população homogênea, o número de mulheres casando com homens do mesmo grupo é $0,9 \times 90=81$ para Ae $0,1 \times 10=1$ para B, ou seja, $82 \%$ dos casamentos seriam endogâmicos. Isso indica que, em populações heterogêneas, a endogamia é menor do que em populações homogêneas, se considerarmos que os casamentos ocorrem aleatoriamente. Por exemplo, considerando apenas brancos e não brancos, podemos dizer que, mesmo se não houvesse associação entre raça dos cônjuges no Brasil e nos Estados Unidos (ou seja, se o casamento inter-racial fosse aleatório), teríamos mais endogamia racial nos Estados Unidos do que no Brasil, simplesmente pelo fato de que a população norte-americana é mais homogênea $(88 \%$ de brancos e $12 \%$ de não brancos - afro-americanos) do que a brasileira ( $54 \%$ de brancos e $45 \%$ de não brancos - pretos e pardos $)^{1}$.

No entanto, como sabemos, existe uma significativa associação estatística na escolha conjugal no que diz respeito à cor dos cônjuges (bem como a outras características). Em outras palavras, sabemos que as escolhas conjugais não são aleatórias. O esquema da Figura 1 parte da ideia de que há forças sociais unindo e separando pessoas pertencentes a diferentes grupos sociais e com diversas características, o que implica dizer que os casamentos não são aleatórios. Por isso, devemos considerar tanto o tamanho dos grupos sociais quanto a associação entre as características dos cônjuges mesmo que não saibamos bem se essa as- 
sociação é fruto de preferências individuais (1) ou de normas dos grupos (2), como já argumentamos. Se imaginássemos que, no exemplo das populações A e B do parágrafo anterior, também houvesse associação estatística entre A e B, teríamos taxas de endogamia variando de acordo tanto com o nível de heterogeneidade/homogeneidade (tamanho dos grupos) quanto com o grau de associação estatística, o que significa que as taxas seriam diferentes das descritas para o caso de casamentos aleatórios. Em outras palavras, precisamos de um modelo que separe o efeito do tamanho dos grupos (da heterogeneidade/homogeneidade) da associação estatística entre características dos cônjuges na escolha marital. Além disso, podemos dizer que, em um modelo que leve em conta o tamanho dos grupos sociais, o grau de associação estatística entre as características dos cônjuges revela as preferências individuais (1) e/ou as normas dos grupos (2) que também conformam os padrões de intercasamento. Na seção sobre a metodologia adotada, apresentamos modelos log-lineares que atendem a essas exigências e que são, portanto, adequados para o estudo dos padrões de intercasamento. Antes, precisamos fazer uma pequena revisão da literatura brasileira sobre seletividade marital por cor e educação.

\section{A ESCOLHA CONJUGAL POR COR NO BRASIL}

Tendo em vista a importância dos intercasamentos para definir as fronteiras entre grupos sociais, não é novidade dizer que o tema dos casamentos inter-raciais e da miscigenação é fundamental para o debate sobre relações raciais no Brasil. De fato, há um conjunto razoavelmente numeroso de estudos sobre casamentos inter-raciais. Os três tipos de abordagem mais frequentemente adotados nesses estudos são: observações antropológicas ou qualitativas, registros civis de casamento e dados agregados (como censos e pesquisas por amostragem populacional). Enquanto os estudos fazendo referência à importância do tema dos casamentos inter-raciais para o entendimento das relações raciais no país são relativamente numerosos, há apenas algumas poucas pesquisas mais minuciosas sobre o tema.

Os estudos usando observação qualitativa e registros civis de casamento tendem a focalizar regiões específicas do país. Analisando registros civis referentes aos anos 1933 e 1934, Pierson (1942) afirma que a incidência de casamentos inter-raciais na Bahia é muito baixa. Em contraste, Azevedo (1966) utiliza métodos antropológicos e sugere que, na década de 1950, praticamente um em cada cinco casamentos 
era inter-racial. Enquanto o trabalho de Pierson não se concentra no tema dos casamentos, Azevedo escreveu diversos artigos especificamente sobre o tema $(1955 ; 1963 ; 1966 ; 1975)$. Nesses estudos, o autor afirma que os padrões de casamento inter-racial seguem uma série de normas ideais e de comportamentos reais.

Essas normas ideais e seus respectivos padrões reais são os seguintes: (1) idealmente, pessoas de cores diferentes podem se casar, mas na prática há sempre desconforto e tensão nas famílias quando ocorrem esses tipos de casamento; (2) o casamento entre homens mais escuros e mulheres mais claras seria mais aceito, e de fato esse tipo de casamento seria mais comum e menos problemático do que o inverso; (3) casamentos de tipos fisicamente mais próximos seriam mais aceitos, mas na prática a distância de cor que separa os tipos diferentes diminui na medida em que os casamentos se dão em classes ou grupos de status mais altos; e (4) casamentos inter-raciais são mais aceitos se os homens mais escuros tiverem status mais alto do que as mulheres, mas, de fato, em casamentos socialmente assimétricos, a diferença de cor é mais aceita do que em casamentos socialmente mais simétricos.

Como veremos mais adiante, há evidências que comprovam a ideia de que homens mais escuros tendem a se casar com mulheres mais claras em maior proporção do que mulheres mais escuras com homens mais claros. Vários estudos qualitativos sugerem esse padrão (Azevedo, 1955; 1963; Willems, 1961). É interessante notar que, embora Azevedo e Pierson tendam a concordar que as relações raciais no Brasil são relativamente harmônicas, ambos observam uma incidência muito baixa de casamentos inter-raciais mesmo na Bahia, que seria o estado mais miscigenado. Além disso, a perspectiva de Azevedo se diferencia à medida que mostra as tensões relacionadas aos casamentos inter-raciais. Em ambos os casos, no entanto, há evidentemente limitações relacionadas aos métodos utilizados, uma vez que estudos qualitativos não possibilitam generalizações sobre os padrões observados.

Além desses estudos, o trabalho mais pormenorizado sobre o tema de que temos conhecimento é a tese de doutorado do padre Austin Staley (1959), intitulada Racial Democracy in Marriage: A Sociological Analysis of Negro-White Intermarriage in Brazilian Culture. A pesquisa de Staley foi bastante detalhada e extensa, tendo utilizado uma série de metodologias distintas: uma análise de registros civis, uma pesquisa amostral sobre a atitude de jovens estudantes, uma análise de con- 
teúdo de textos literários e um conjunto de entrevistas pormenorizadas com casais inter-raciais.

Destacamos as seguintes conclusões de Staley, baseadas sobretudo nas entrevistas que fez: (1) no Brasil, uma boa proporção de casais inter-raciais revela um total desconhecimento da existência de preconceito racial nos círculos familiares e de amizade, enquanto um segundo tipo de casal se caracteriza pelo isolamento social e também não percebe a existência de preconceito (cerca de $70 \%$ dos casais inter-raciais estudados por Staley estão nessas duas situações); (2) graus variados de preconceito são observados em todas as classes e partes do Brasil; (3) quanto mais elevada a posição social, maior a resistência ao casamento inter-racial.

Embora Staley tenha mostrado que, a partir dos registros civis, na década de 1950 havia uma incidência muito baixa de casamentos inter-raciais, ele dá mais ênfase ao fato de a maioria dos casais que entrevistou ter desconhecimento de preconceito racial. Nesse sentido, conclui que:

[...] a sociedade brasileira parece ser capaz de conciliar o inconciliável. Pode mesmo haver uma "conspiração natural inconsciente" para ignorar o conflito existente entre a norma geral de igualdade racial e normas específicas governando relações inter-raciais ao nível da família [...]. A democracia racial brasileira permanece como uma das mais admiráveis na sociedade humana moderna (ibidem:127).

Enquanto Azevedo (1955) mostra os conflitos e tensões relacionados aos casamentos inter-raciais, Staley (1959) enfatiza a relativa falta de percepção de preconceito. Talvez essas conclusões opostas estejam relacionadas ao fato de que Azevedo analisou principalmente os casamentos inter-raciais nos grupos de elite e Staley em uma gama mais ampla de estratos sociais. De fato, ambos sugerem que os casamentos inter-raciais tenderiam a ser mais conflituosos e tensos à medida que se sobe na escala de posições socioeconômica. De qualquer forma, ambos os estudos baseiam suas conclusões em amostras não representativas da população brasileira.

Foi apenas na década de 1980 que estudos sobre padrões nacionais de casamentos inter-raciais foram realizados. Usando dados do censo de 1980, Silva (1987) chega a algumas conclusões relevantes e faz algumas previsões sobre as tendências dos casamentos inter-raciais. A primeira 
conclusão é que, em termos de casamentos, os pardos estão mais próximos dos brancos do que dos pretos. Como afirma o autor,

[...] contrariamente ao que sabemos das distâncias socioeconômicas entre os grupos de cor, o grupo pardo ocupa uma posição realmente intermediária entre brancos e pretos. De fato, parece mesmo estar ligeiramente mais próximo do grupo branco do que do grupo preto. O padrão dicotômico observado nos estudos socioeconômicos, isto é, brancos claramente diferenciados de pardos e pretos, estes últimos ocupando posição muito próxima entre si, claramente não se reproduz nos padrões de distâncias sociais implícitas nos padrões de casamento inter-racial no Brasil. Estes resultados sugerem que as distâncias sociais no casamento não são de natureza primariamente socioeconômica, seguindo talvez outras hierarquias como, por exemplo, hierarquias de status ou de prestígio (ibidem:50).

Silva destaca que esse padrão favorece a miscigenação e prevê uma diminuição crescente não apenas das taxas absolutas de endogamia racial mas também das barreiras, dificultando os casamentos inter-raciais. No que diz respeito às taxas absolutas de endogamia, o trabalho de Telles (2004) confirma as previsões de Silva (1992), ao passo que, ao analisar coortes de idade, Silva (1987) mostra uma tendência à diminuição das distâncias sociais entre os grupos de cor. Em outro artigo, o autor (1992) mostra uma tendência à diminuição das taxas de casamento inter-racial entre as diversas regiões do Brasil, fato que também é confirmado no estudo de Telles (2004) sobre o tema. Embora Silva e Telles apresentem algumas análises sobre a relação entre casamentos inter-raciais e nível educacional dos cônjuges, sugerindo que não há interferência entre padrões de casamento por cor e por nível educacional, ambos os autores se limitam a analisar taxas absolutas de casamento e sua relação com níveis educacionais.

Neste artigo, fazemos a análise da relação entre seletividade marital por cor e educação não apenas no que diz respeito às mudanças demográficas representadas nas taxas absolutas mas também no nível da associação estatística que, como vimos anteriormente, pode ser usada para descrever as preferências individuais e/ou as normas sociais que estão relacionadas aos padrões observados de endogamia e exogamia. Dessa perspectiva, parece realmente haver uma lacuna na literatura, tendo em vista que houve tanto uma diminuição da desigualdade racial em termos de acesso à educação quanto um aumento dos casamentos entre pessoas com educação diferente. Diversos estudos mostram 
que houve uma diminuição no hiato educacional entre brancos, pardos e pretos desde 1960 (Beltrão, 2005). Além disso, as barreiras educacionais da seletividade marital se tornaram significativamente mais permeáveis durante as décadas de 1980 e 1990 (Silva, 2003). Será que essas mudanças estão relacionadas ao aumento dos casamentos inter-raciais? Essa é a principal pergunta que pretendemos responder neste artigo.

\section{OS DADOS E OS MODELOS}

Para analisar a seletividade matrimonial por cor e educação, utilizamos a classificação de grupos de cor padrão no Brasil, que os divide entre brancos, pardos e pretos. Dessa forma, excluímos os amarelos e indígenas não apenas porque há modificação na classificação desses dois grupos entre 1960 e 2000, mas, sobretudo, porque constituem grupos extremamente pequenos e não podem ser significativamente incluídos nas análises estatísticas elaboradas neste artigo. Quanto aos grupos educacionais, fazemos as seguintes distinções: 0 a 3 anos (sem escolaridade e/ou elementar incompleto); 4 a 7 anos (elementar completo); 8 anos (primário completo); 9 a 11 anos (alguma educação secundária); e 12 ou mais anos de escolaridade (alguma educação universitária). Analisamos três censos populacionais brasileiros cobrindo os quarenta anos, de 1960 a 2000. Para 1960, utilizamos uma amostra de $1 \%$ do censo populacional; para 1980 e 2000, uma amostra de $5 \%$ dos respectivos censos. Tendo em vista que as amostras para 1980 e 2000 são muito grandes e poderiam influenciar os resultados dando maior peso a esses dois últimos anos, seguimos o procedimento padrão de multiplicar cada amostra por uma constante com o objetivo de obter três bancos de dados com número de casos equivalente (Raymo e Xie, 2000). Além disso, as análises estão restritas a casais em que marido e esposa tinham entre 20 e 34 anos no ano do censo, com o objetivo de restringir a amostra a pessoas que estejam provavelmente em seu primeiro casamento, tendo em vista que os padrões de segundos casamentos podem ser diferentes (Mare, 1991). Obviamente, estamos apenas presumindo que as pessoas estão em seu primeiro casamento, porque não temos a informação completa. De qualquer forma, essa pressuposição faz sentido em termos do que se sabe sobre padrões de casamento.

Tal organização dos bancos de dados implica dizer que analisamos o "estoque de casamentos" em cada um dos três anos estudados, ou seja, investigamos a associação entre características das pessoas entre 20 e 34 anos que estavam casadas no momento em que o censo foi coletado. 
Uma alternativa, geralmente preferível, seria analisar a incidência de casamentos em um determinado período, o que exigiria o uso de dados longitudinais ou de painel para verificar as chances de casar com pessoas tendo diferentes características. Esse tipo de abordagem é preferível porque permite calcular tanto as chances de as pessoas se casarem quanto o momento ou tempo em que esses eventos ocorrem (Blossfeld, 2003). No Brasil, não há dados longitudinais que permitam esse tipo de desenho analítico, embora alguns bancos de dados possuam perguntas retrospectivas sobre o momento em que as pessoas se casaram e poderiam ser usados, com alguma limitação, para estudar a incidência de casamentos usando modelos de sobrevivência. De qualquer modo, bancos de dados sobre estoques de casamento vêm sendo utilizados com sucesso em várias pesquisas sobre tendências de longa duração na seletividade matrimonial (Kalmijn, 1991b; Mare, 1991; Schwartz e Mare, 2005).

Aparentemente, no Brasil, as chances de pessoas entre 20 e 34 anos de diferentes grupos educacionais e de cor se casarem não se modificou muito entre 1960 e 2000. Entre os brancos, 62\% em 1960 e 57\% em 2000 estavam casados quando tinham entre 20 e 34 anos, enquanto que entre os pardos esse percentual era de $65 \%$ em 1960 e $57 \%$ em 2000; entre os pretos, de $57 \%$ em 1960 e $54 \%$ em 2000 . Brancos e pardos tinham em geral chances um pouco maiores do que pretos de estarem casados na faixa de idade que estamos estudando. Além disso, como vemos, há também uma leve tendência geral de diminuição no percentual de pessoas casadas entre 1960 e 2000 em todos os grupos de cor.

Os dados para educação revelam não apenas que o percentual de pessoas com menos educação que estão casadas é levemente menor do que o percentual para pessoas mais educadas, mas que há também a mesma tendência de diminuição do percentual de pessoas casadas entre 1960 e 2000. Todas essas variações percentuais são relativamente pequenas, o que indica que não levar em conta as probabilidades de os indivíduos se casarem não estaria enviesando substancialmente as análises que fazemos. Em outras palavras, o estudo do estoque de casamentos nos anos dos censos provavelmente permite analisar com relativa segurança as tendências de endogamia e exogamia na sociedade brasileira.

Outra questão metodológica a qual já nos referimos diz respeito à distinção entre os efeitos da composição populacional (tamanho dos grupos de cor e de educação) e da associação estatística entre características dos cônjuges. Essa associação poderia ser usada para definir o efei- 
to das normas dos grupos e/ou das preferências individuais influenciando os padrões de casamento observados. Para dar conta dessa distinção, utilizamos modelos log-lineares que controlam a associação estatística pelo tamanho dos grupos de cor e de educação. Dessa forma, temos como separar os efeitos da composição populacional da associação estatística líquida entre as características dos cônjuges.

Inicialmente, na próxima seção, apresentamos as taxas absolutas de casamento por cor e nível educacional de maridos e esposas. Em seguida, utilizamos modelos log-lineares para analisar a tabela cruzando cor do marido com cor da esposa e ano do censo (1960, 1980 e 2000). O principal objetivo é estimar um modelo que represente bem as barreiras ao casamento inter-racial e as propensões à endogamia em cada grupo de cor. No passo seguinte, analisamos a tabela cruzando nível educacional do marido com nível educacional da esposa e ano do censo, também visando descrever as principais barreiras educacionais e as chances de endogamia. Tendo em vista que os modelos para analisar as tendências entre 1960 e 2000, tanto da seletividade marital por cor quanto da por educação, são muito semelhantes, apresentamos a seguir apenas o modelo para a seletividade por cor (o modelo para analisar a seletividade educacional é o mesmo, com duas linhas e duas colunas a mais). A equação do modelo log-linear é:

$\ln \left(\mathrm{F}_{\mathrm{ijt}}\right)=\mu_{0}+\beta_{\mathrm{i}}{ }^{\mathrm{H}}+\beta_{\mathrm{j}}{ }^{\mathrm{W}}+\beta_{\mathrm{t}}^{\mathrm{T}}+\beta_{\mathrm{it}}{ }^{\mathrm{HT}}+\beta_{\mathrm{jt}}{ }^{\mathrm{WT}}+\left(\mathrm{v}_{\mathrm{ij}} \beta_{\mathrm{t}}\right)^{\mathrm{HWT}}$

em que $\ln \left(\mathrm{F}_{\mathrm{ijt}}\right)$ é o logaritmo natural da frequência esperada na célula ( $\mathrm{i}$, $\mathrm{j}, \mathrm{t}$ ); $\mathrm{i}=$ cor do marido; $\mathrm{j}=$ cor da esposa; $\mathrm{t}=$ ano do censo; $\beta_{\mathrm{i}}{ }^{\mathrm{H}}=$ distribuição marginal da cor do marido; $\beta_{\mathrm{j}}{ }^{\mathrm{W}}=$ distribuição marginal da cor da esposa; $\beta_{\mathrm{t}}^{\mathrm{T}}=$ distribuição marginal dos censos; $\beta_{\mathrm{it}}{ }^{\mathrm{HT}}$ e $\beta_{\mathrm{jt}}{ }^{\mathrm{WT}}$ representam as interações entre cor do marido e ano do censo e cor da esposa e ano do censo, respectivamente. $O$ termo $\left(\nu_{\mathrm{ij}} \beta_{\mathrm{t}}\right)^{\mathrm{HWT}}$ define a interação entre cor de maridos e de esposas e sua variação ao longo do tempo. Nesse termo, se $\beta_{\mathrm{t}}$ for definido como tendo o valor 1 , temos o modelo de associação constante entre 1960 e 2000; caso $\beta_{\mathrm{t}}$ varie livremente, temos um modelo especificando mudanças temporais nas barreiras de cor. Para o termo $v_{\mathrm{ij}}$, as seguintes condições se aplicam:
$v_{i j}=\quad\{$
$\sum_{u=j}^{i-1} \mathrm{v}_{u} \quad$ para $i>j$,
$\sum_{u=0}^{j-1} v_{u} \quad$ para $i<j$,
$\xi_{i} \quad$ para $i=j$. 
Essas condições definem que a interação entre cor de maridos e de esposas é definida por um padrão de barreiras simétricas (iguais para homens e mulheres) entre os três grupos de cor e pela homogamia entre pardos (a homogamia entre brancos e entre pretos também é dada pelas barreiras). O logaritmo das chances de intercasamento relativas a esse modelo é apresentado na Tabela 1:

Tabela 1

Parâmetros para os Efeitos de Barreira e

Homogamia no Modelo de Seletividade por Cor no Casamento

\begin{tabular}{l|c|c|c}
\hline \multirow{2}{*}{ Cor do Marido } & \multicolumn{3}{|c}{ Cor da Esposa } \\
\cline { 2 - 4 } & Branca & Parda & Preta \\
\hline Branca & 0 & $v 1$ & $v 1+v 2$ \\
Parda & $v 1$ & $\xi 2$ & $v 2$ \\
Preta & $v 1+v 2$ & $v 2$ & 0 \\
\hline
\end{tabular}

Elaboração dos autores.

Como mencionamos, o modelo para seletividade educacional no casamento também é um modelo de barreiras como o apresentado na Tabela 1 para a seletividade por cor. A diferença é que, em vez de estimar apenas duas barreiras, inclui quatro dessas barreiras e, em vez de estimar apenas um parâmetro de homogamia, inclui três (para as três categorias educacionais intermediárias). $\mathrm{Na}$ análise das chances de casamento inter-racial, a Equação 1 define o "modelo de barreiras de cor", que pode apresentar associação constante ao longo dos três anos (Modelo 3 da Tabela 6) ou variação ao longo do tempo (Modelo 4 da Tabela 6). $\mathrm{Na}$ análise dos casamentos intereducacionais, a Equação 1 (agora ampliada porque contém duas linhas e duas colunas a mais, como explicado anteriormente) define o "modelo de barreiras educacionais", que é estimado nas seguintes combinações: (1) sem incluir os três termos de homogamia $(\xi)$ e assumindo associação constante no tempo (Modelo 4 da Tabela 7); (2) incluindo os termos de homogamia e assumindo associação constante no tempo (Modelo 5 da Tabela 7); (3) deixando o padrão de homogamia constante ao longo do tempo, mas permitindo que as "barreiras educacionais" (v1, v2, v3 e v4) variem no tempo (Modelo 6 da Tabela 7); e adicionando à especificação anterior (Modelo 6 da Tabela 7) um termo para capturar a variação ao longo do tempo nas chances de hipergamia em relação à hipogamia (Modelo 8 da Tabela 7), ou seja, maior chance de mulheres se casarem com ho- 
mens mais educados do que elas. Nas análises, também são usados outros modelos simples para a análise da associação entre cor ou educação de maridos e esposas: o modelo de independência (Modelos 1 das Tabelas 6 e 7); o modelo de associação completa (Modelo 2 das Tabelas 6 e 7); e o modelo de simetria (Modelo 3 da Tabela 7) ${ }^{2}$.

Depois de estimar modelos para a seletividade educacional e por cor, elaboramos outro mais complexo para analisar conjuntamente a variação dessas duas formas de seletividade entre 1960 e 2000. Isso implica ajustar modelos a uma tabela de contingência com cinco variáveis: cor do marido, cor da esposa, educação do marido, educação da esposa e ano do censo. A equação geral é a seguinte:

$\ln \left(\mathrm{F}_{\mathrm{ijklt}}\right)=\mu_{0}+\beta_{\mathrm{i}}^{\mathrm{H}}+\beta_{\mathrm{j}}{ }^{\mathrm{W}}+\beta_{\mathrm{k}}{ }^{\mathrm{E}}+\beta_{1}^{\mathrm{S}}+\beta_{\mathrm{t}}{ }^{\mathrm{T}}+\beta_{\mathrm{ik}}{ }^{\mathrm{HE}}+\beta_{\mathrm{j} 1}{ }^{\mathrm{WS}}+\beta_{\mathrm{it}}{ }^{\mathrm{HT}}+\beta_{\mathrm{jt}}{ }^{\mathrm{WT}}+\beta_{\mathrm{kt}}{ }^{\mathrm{ET}}+$ $\beta_{\mathrm{lt}}^{\mathrm{ST}}+\beta_{\mathrm{ij}}^{\mathrm{HW}}+\beta_{\mathrm{kl}}^{\mathrm{ES}}+\beta_{\mathrm{ljt}}^{\mathrm{HWT}}+\beta_{\mathrm{jkl}}{ }^{\mathrm{WST}}+\left(\mathrm{v}_{\mathrm{ij}} \beta_{\mathrm{t}}\right)^{\mathrm{HWT}}+\left(\mathrm{v}_{\mathrm{kl}} \beta_{\mathrm{t}}\right)^{\mathrm{EST}}$

em que $\ln \left(\mathrm{F}_{\mathrm{ijklt}}\right)$ é o logaritmo natural da frequência esperada na célula $(i, j, k, l, t)$, cujos subscritos são: $i=$ cor do marido; $j$ = cor da esposa; $k$ = educação do marido; 1 = educação da esposa; $t=$ ano do censo. Os parâmetros estimados são: $\beta_{\mathrm{i}}{ }^{\mathrm{H}}=$ distribuição marginal da cor do marido; $\beta_{\mathrm{j}}{ }^{\mathrm{W}}$ = distribuição marginal da cor da esposa; $\beta_{\mathrm{k}}{ }^{\mathrm{E}}=$ distribuição marginal da educação do marido; $\beta_{1}^{\mathrm{S}}=$ distribuição marginal da educação da esposa; $\beta_{\mathrm{t}}^{\mathrm{T}}=$ distribuição marginal dos censos; $\beta_{\mathrm{ik}}{ }^{\mathrm{HE}}, \beta_{\mathrm{jl}}{ }^{\mathrm{WS}}, \beta_{\mathrm{it}}{ }^{\mathrm{HT}}, \beta_{\mathrm{jt}}{ }^{\mathrm{WT}}, \beta_{\mathrm{kt}}^{\mathrm{ET}}$, $\beta_{\mathrm{lt}}^{\mathrm{ST}}, \beta_{\mathrm{ij}}^{\mathrm{HW}}$ e $\beta_{\mathrm{kl}} \mathrm{ES}$ representam, respectivamente, as interações entre cor do marido e educação do marido, cor da esposa e educação da esposa, cor do marido e ano do censo, cor da esposa e ano do censo, educação do marido e ano do censo, educação da esposa e ano do censo, cor do marido e cor da esposa, educação do marido e educação da esposa. O modelo também inclui termos para a interação entre as seguintes três variáveis: cor do marido, educação do marido e ano do censo $\left(\beta_{\mathrm{ikt}}{ }^{\mathrm{HET}}\right)$; cor da esposa, educação da esposa e ano do censo $\left(\beta_{j \mathrm{lt}}{ }^{\text {WST }}\right)$.

Finalmente, os parâmetros de maior interesse são os dois últimos, estimando a variação das associações entre: cor dos cônjuges ao longo do tempo $\left(v_{i j} \beta_{t}\right)^{H W T}$ e educação dos cônjuges ao longo do tempo $\left(v_{k l} \beta_{t}\right)^{E S T}$. Esses dois termos seguem o padrão e as condições especificados para a Equação 1 e são, respectivamente, as "barreiras de cor" (que podem ou não incluir a homogamia entre pardos) e as "barreiras educacionais" (que podem ou não incluir a homogamia nas três categorias educacionais intermediárias). Na seção Seletividade Marital por Cor e Educação, Tabela 8, testamos essas diferentes combinações nos Modelos 3, 4, $5,6,7,8$, e 9 . Tendo em vista que os modelos log-lineares seguem estru- 
tura hierárquica, fazemos os testes partindo de um modelo de base (Modelo 1 da Tabela 8) que só inclui o ajuste das distribuições marginais e das interações de segunda ordem, e, em seguida, incluímos os termos de interação de terceira ordem para a associação entre cor e educação do marido e cor e educação da esposa (Modelo 2 da Tabela 8).

Nas análises empíricas, também testamos se havia interação entre todas as características dos cônjuges $\left(\beta_{\mathrm{ijk} \mathrm{k}}{ }_{\mathrm{HWS}}\right)$ e entre todas as características dos cônjuges e o ano do censo $\left(\beta_{\mathrm{ijklt}}{ }^{\text {HWEST }}\right)$. Como mostramos adiante, essas interações não são estatisticamente significativas. Todos os modelos estimados são usuais e suas especificações podem ser obtidas na literatura (Hout, 1983; Powers e Xie, 2000). Além disso, modelos para testar a hipótese das trocas de status (Merton, 1941) também foram estimados, mas não se ajustaram bem aos dados, indicando que as barreiras de cor e educação são as características predominantes do mercado matrimonial brasileiro (Gullickson, 2006). Como usual, a referência aos termos utilizados nos modelos apresentados nas tabelas seguintes são feitas apenas utilizando os termos sobrescritos das Equações 1 e 2 anteriores ${ }^{3}$.

\section{TAXAS ABSOLUTAS DE SELETIVIDADE CONJUGAL}

A endogamia por cor da pele parece ter realmente diminuído no Brasil, como previam os estudos anteriores, passando de $88 \%$ dos casamentos, em 1960, para 80\% em 1980 e $69 \%$ em 2000 (ver Tabela 2). Como argumentamos, há dois fatores relacionados a esse aumento: (1) mudanças na composição populacional, expressando causas demográficas; e (2) mudanças na associação estatística entre cor de cônjuges, expressando preferências individuais ou normas sociais. Se não houvesse o efeito de preferências individuais e/ou normas sociais, ou seja, se não houvesse associação estatística entre a cor dos cônjuges, as taxas de endogamia seriam: 51\% em 1960, 48\% em 1980 e 45\% em 20004. Portanto, mesmo que não houvesse associação estatística entre cor dos cônjuges, haveria um percentual relativamente alto de casamentos endogâmicos por cor que seria produto unicamente do tamanho relativo dos grupos de cor no Brasil.

Estudos anteriores mostraram claramente que fatores demográficos e normas sociais e/ou preferências individuais conformam os padrões de casamentos inter-raciais no Brasil. No entanto, nenhum estudo verificou se esses efeitos sobre as taxas de casamento inter-racial estão rela- 
Tabela 2

Cor do Marido e Cor da Esposa

$(1960,1980$ e 2000$)$

\begin{tabular}{|c|c|c|c|c|c|}
\hline $\begin{array}{l}1960 \\
(N=41.120)\end{array}$ & \multicolumn{5}{|c|}{ Cor da Esposa } \\
\hline \multirow{5}{*}{ Cor do Marido } & & Branca & Parda & Preta & Total (\%) \\
\hline & Branca & 61,2 & 3,7 & 0,4 & 65,3 \\
\hline & Parda & 4,8 & 21,2 & 0,9 & 26,9 \\
\hline & Preta & 0,7 & 1,4 & 5,7 & 7,8 \\
\hline & Total (\%) & 66,7 & 26,3 & 7,0 & 100,0 \\
\hline $\begin{array}{l}1980 \\
(\mathrm{~N}=308.432)\end{array}$ & \multicolumn{5}{|c|}{ Cor da Esposa } \\
\hline \multirow{5}{*}{ Cor do Marido } & & Branca & Parda & Preta & Total (\%) \\
\hline & Branca & 50,6 & 6,7 & 0,6 & 57,9 \\
\hline & Parda & 9,3 & 26,4 & 1,1 & 36,8 \\
\hline & Preta & 0,8 & 1,5 & 3,0 & 5,3 \\
\hline & Total (\%) & 60,7 & 34,6 & 4,7 & 100,0 \\
\hline $\begin{array}{l}2000 \\
(N=450.327)\end{array}$ & \multicolumn{5}{|c|}{ Cor da Esposa } \\
\hline \multirow{5}{*}{ Cor do Marido } & & Branca & Parda & Preta & Total $(\%)$ \\
\hline & Branca & 40,3 & 10,8 & 1,6 & 52,7 \\
\hline & Parda & 13,0 & 26,1 & 1,3 & 40,4 \\
\hline & Preta & 2,1 & 2,2 & 2,5 & 6,8 \\
\hline & Total (\%) & 55,4 & 39,1 & 5,4 & 100,0 \\
\hline
\end{tabular}

Elaboração dos autores.

cionados a outras mudanças importantes que ocorreram na sociedade brasileira. Em particular, houve uma diminuição da desigualdade educacional entre os grupos de cor, bem como um aumento dos casamentos intereducacionais. A Tabela 3 apresenta a vantagem educacional média entre os grupos de cor no Brasil, ou seja, a razão entre as médias de anos de educação de cada grupo de cor. É evidente que houve uma significativa diminuição nessas vantagens educacionais médias de brancos em relação tanto a pardos quanto a pretos entre 1960 e 2000. Essa mudança se deve, em grande medida, à expansão educacional que ocorreu no país desde 1960 e pode estar relacionada ao aumento dos casamentos inter-raciais. 
Tabela 3

Vantagem Educacional Média entre os

Grupos de Cor no Brasil

$(1960,1980$ e 2000)

\begin{tabular}{l|c|c|c}
\hline Vantagem (Razão) Educacional & $\mathbf{1 9 6 0}$ & $\mathbf{1 9 8 0}$ & $\mathbf{2 0 0 0}$ \\
\hline Branco/pardo & 2,2 & 1,7 & 1,3 \\
Branco/preto & 2,5 & 1,9 & 1,3 \\
Pardo/preto & 1,1 & 1,1 & 1,0 \\
\hline
\end{tabular}

Elaboração dos autores.

A expansão do acesso ao sistema educacional também representou uma enorme diminuição da desigualdade de gênero, uma vez que as mulheres passaram a ter cada vez mais acesso à educação de fato, como já vimos, revertendo a vantagem educacional que os homens tinham. Essa mudança está, provavelmente, relacionada a um aumento dos casamentos intereducacionais no Brasil. Enquanto em 1960 cerca de $70 \%$ das pessoas entre 20 e 34 anos tinham menos de quatro anos de escolaridade, em 2000 apenas $24 \%$ dos homens e 19\% das mulheres tinham menos de quatro anos de educação. Em outras palavras, a expansão do sistema educacional tornou a distribuição educacional da população mais heterogênea (pessoas mais distribuídas por diferentes níveis educacionais), o que, como vimos, leva necessariamente a uma diminuição da endogamia (Blau e Schwartz, 1984; Blau, Blum e Schwartz,1982). De fato, $79,2 \%$ dos casamentos eram educacionalmente homogâmicos em 1960, 59,4\% o eram em 1980 e 48,1\% em 2000 (ver Tabela 4 a seguir). Inversamente, podemos dizer que houve um aumento significativo dos casamentos intereducacionais no Brasil. De novo, lembramos que, se não houvesse associação estatística entre os níveis educacionais de maridos e esposas e se apenas as forças relacionadas à composição populacional estivessem presentes, as taxas de homogamia educacional seriam muito menores, mais precisamente $56 \%$ em 1960, 32\% em 1980 e $26 \%$ em 2000.

Assim, quando examinamos o quadro da escolha conjugal considerando os níveis de escolaridade do casal, os resultados gerais são semelhantes, tanto estrutural quanto temporalmente, ao caso do casamento inter-racial. Verifica-se igualmente um largo predomínio do casamento homogâmico, mas o nível da homogamia, como vimos, vem caindo rapidamente no tempo, a ponto de em 2000 já ser possível verificar o predomínio do casamento heterogâmico. No entanto, um ponto de di- 
ferenciação em relação ao caso da cor deve ser lembrado: diz respeito ao perfil educacional das esposas, que, de uma situação inicial de desvantagem em relação aos esposos em 1960, em 2000 já haviam efetuado uma inversão de posição, agora ultrapassando claramente o nível de escolaridade de seus parceiros.

Tabela 4

Educação (Anos de Escolaridade) do Marido e da Esposa

(1960 a 2000)

\begin{tabular}{l|l|c|c|c|c|c|c}
\hline $\begin{array}{l}\text { 1960 } \\
(\mathbf{N}=\mathbf{4 1 . 1 2 0 )}\end{array}$ & \multicolumn{7}{|c}{ Educação da Esposa } \\
\hline & & 0 a 3 & 4 a 7 & 8 & 9 a 11 & 12 ou mais & Total (\%) \\
\cline { 2 - 8 } & 0 a 3 & 63,9 & 6,1 & 0,2 & 0,1 & 0,0 & $\mathbf{7 0 , 3}$ \\
Educação do & 4 a 7 & 8,1 & 13,8 & 0,8 & 0,6 & 0,0 & $\mathbf{2 3 , 3}$ \\
Marido & 8 & 0,3 & 1,3 & 0,7 & 0,3 & 0,0 & $\mathbf{2 , 6}$ \\
& 9 a 11 & 0,1 & 1,0 & 0,5 & 0,7 & 0,0 & $\mathbf{2 , 3}$ \\
& 12 ou mais & 0,0 & 0,3 & 0,4 & 0,5 & 0,2 & $\mathbf{1 , 4}$ \\
\cline { 2 - 8 } & Total (\%) & $\mathbf{7 2 , 4}$ & $\mathbf{2 2 , 5}$ & $\mathbf{2 , 6}$ & $\mathbf{2 , 2}$ & $\mathbf{0 , 2}$ & $\mathbf{1 0 0 , 0}$ \\
\hline
\end{tabular}

\begin{tabular}{l|l|c|c|c|c|c|c}
\hline $\begin{array}{l}1980 \\
(\mathbf{N}=308.432)\end{array}$ & \multicolumn{7}{|c}{ Educação da Esposa } \\
\hline & & 0 a 3 & 4 a 7 & 8 & 9 a 11 & 12 ou mais & Total (\%) \\
\cline { 2 - 8 } & 0 a 3 & 30,4 & 10,0 & 0,7 & 0,6 & 0,0 & 41,7 \\
\multirow{4}{*}{$\begin{array}{l}\text { Educação do } \\
\text { Marido }\end{array}$} & 4 a 7 & 9,1 & 20,2 & 2,6 & 2,7 & 0,4 & 35,0 \\
& 8 & 0,8 & 2,9 & 1,6 & 1,4 & 0,3 & 7,0 \\
& 9 a 11 & 0,4 & 2,5 & 1,5 & 4,1 & 1,1 & $\mathbf{9 , 6}$ \\
& 12 ou mais & 0,1 & 0,5 & 0,5 & 2,4 & 3,2 & $\mathbf{6 , 7}$ \\
\cline { 2 - 8 } & Total (\%) & $\mathbf{4 0 , 8}$ & $\mathbf{3 6 , 1}$ & $\mathbf{6 , 9}$ & $\mathbf{1 1 , 2}$ & $\mathbf{5 , 0}$ & $\mathbf{1 0 0 , 0}$ \\
\hline
\end{tabular}

\begin{tabular}{l|l|c|c|c|c|c|c}
\hline \multirow{2}{2}{$\mathbf{2 0 0 0}$} \\
$\mathbf{( N = 4 5 0 . 3 2 7 )}$ & \multicolumn{7}{|c}{ Educação da Esposa } \\
\hline & & 0 a 3 & 4 a 7 & 8 & 9 a 11 & 12 ou mais & Total (\%) \\
\cline { 2 - 9 } & 0 a 3 & 11,3 & 9,8 & 1,2 & 1,8 & 0,1 & $\mathbf{2 4 , 2}$ \\
Educação do & 4 a 7 & 5,9 & 19,2 & 4,2 & 6,9 & 0,5 & 36,7 \\
Marido & 8 & 0,8 & 3,8 & 2,7 & 3,5 & 0,4 & $\mathbf{1 1 , 2}$ \\
& 9 a 11 & 0,8 & 4,3 & 2,8 & 11,9 & 2,1 & $\mathbf{2 1 , 9}$ \\
& 12 ou mais & 0,1 & 0,3 & 0,3 & 2,1 & 3,1 & $\mathbf{5 , 9}$ \\
\cline { 2 - 9 } & Total (\%) & $\mathbf{1 8 , 9}$ & $\mathbf{3 7 , 4}$ & $\mathbf{1 1 , 2}$ & $\mathbf{2 6 , 2}$ & $\mathbf{6 , 2}$ & $\mathbf{1 0 0 , 0}$ \\
\hline
\end{tabular}

Elaboração dos autores. 
Com o objetivo de verificar se há evidências de relação trivariada entre o nível educacional dos cônjuges e a endogamia por grupo de cor, calculamos as taxas de endogamia por cor para cada nível educacional de maridos e esposas. Esses resultados indicam que, entre os homens brancos, 94\% casaram com mulheres brancas em 1960 e 76\% em 2000. Tendência semelhante ocorreu para a endogamia das mulheres brancas, que passou de $92 \%$ em 1960 para $73 \%$ em 2000. As endogamias de homens e mulheres brancas são maiores entre os grupos mais educados e menores entre os menos educados, e acompanham a mesma tendência de diminuição entre 1960 e 2000 para todos os níveis educacionais. Entre homens e mulheres pardos também observamos a tendência de diminuição das endogamias gerais e específicas para cada grupo educacional entre 1960 e 2000, mas, ao contrário do que ocorreu com os brancos, as endogamias, nesse caso, tendem a ser maiores para os níveis educacionais inferiores e menores para os níveis superiores. Finalmente, para os pretos também observamos a tendência geral de diminuição das taxas de endogamia por cor entre 1960 e 2000. Para os homens pretos há mais endogamia por cor nos grupos educacionais mais baixos e menos para os grupos educacionais mais altos, ao passo que para as mulheres pretas observamos que, em 1980, havia endogamia por cor maior nos grupos educacionais mais elevados do que nos menos elevados. Em 2000, as endogamias por cor das mulheres pretas são semelhantes em todos os níveis educacionais.

Ao todo, esses padrões de endogamia por cor em cada nível educacional sugerem que a endogamia por cor varia de acordo com o nível educacional de homens e de mulheres, mas não mostram que a endogamia por cor é um reflexo da endogamia educacional. Na seção Seletividade Marital por Cor e Educação, utilizando um modelo adequado, analisamos com mais cuidado essa hipótese.

Antes de analisarmos mais detalhadamente a associação entre características de maridos e esposas, vale a pena observar algumas informações relevantes para questões já levantadas pela literatura sobre seletividade marital. Na Tabela 5, apresentamos as taxas de hipogamia por cor, percentual de mulheres casando com homens mais claros, e hipergamia por cor, percentual de mulheres casando com homens mais escuros. Em 1960, 42\% das mulheres em uniões exogâmicas por cor se casaram com homens mais claros do que elas e $58 \%$ com homens mais escuros. Em 2000, esses percentuais permaneceram semelhantes, sendo, respectivamente, $44 \%$ e $56 \%$. Como previsto na literatura, é mais fácil 
encontrar mulheres casadas com homens mais escuros do que o inverso. Essa tendência não se modificou durante os quarenta anos estudados. Cabe lembrar que há uma leve tendência para mulheres pretas permanecerem solteiras, como observado na seção Taxas Absolutas de Seletividade Conjugal.

Verificamos um padrão diferente para a tendência de mulheres se casarem com homens mais educados (hipergamia educacional). Em 1960, entre todas as mulheres em uniões educacionalmente heterogâmicas, $84 \%$ se casaram com homens mais educados, ao passo que, em 2000, essa proporção diminuiu para 55\%. De fato, na seção Seletividade Marital por Educação, estimamos um modelo incluindo um parâmetro

Tabela 5

Endogamia Racial e Educacional Total, Hipogamia e Hipergamia Racial e Educacional no Brasil

$(1960,1980$ e 2000)

$(\%)$

\begin{tabular}{l|l|c|c|c}
\hline Cor & & $\mathbf{1 9 6 0}$ & $\mathbf{1 9 8 0}$ & $\mathbf{2 0 0 0}$ \\
\hline & Endogamia por cor total & 88,0 & 80,0 & 69,0 \\
& Homem com mulher mais escura & 5,0 & 8,4 & 13,7 \\
& Homem com mulher mais clara & 7,0 & 11,7 & 17,3 \\
Total & $\mathbf{1 0 0 , 0}$ & $\mathbf{1 0 0 , 0}$ & $\mathbf{1 0 0 , 0}$ \\
& Homem com mulher mais escura & 42,0 & 41,8 & 44,3 \\
& (Hipogamia racial dada endogamia) & & & \\
& Homem com mulher mais clara & 58,0 & 58,2 & 55,7 \\
& (Hipergamia racial dada endogamia) & & & \\
& Total & $\mathbf{1 0 0 , 0}$ & $\mathbf{1 0 0 , 0}$ & $\mathbf{1 0 0 , 0}$ \\
\hline Educação & \multicolumn{2}{|c}{} & \\
\hline & Endogamia educacional total & 79,2 & 59,4 & 48,1 \\
& Mulher com homem menos educado & 8,1 & 19,7 & 30,6 \\
& Mulher com homem mais educado & 12,6 & 20,8 & 21,3 \\
& Total & $\mathbf{1 0 0 , 0}$ & $\mathbf{1 0 0 , 0}$ & $\mathbf{1 0 0 , 0}$ \\
& Mulher com homem menos educado & 15,9 & 35,0 & 44,1 \\
& (Hipogamia feminina) & 84,1 & 65,0 & 55,9 \\
& Mulher com homem mais educado & $\mathbf{1 0 0 , 0}$ & $\mathbf{1 0 0 , 0}$ & $\mathbf{1 0 0 , 0}$ \\
\hline
\end{tabular}

Elaboração dos autores.

Nota: Percentuais podem ultrapassar $100 \%$ por motivos de arredondamento. 
para capturar a associação entre homens mais educados e mulheres menos educadas (hipergamia educacional) e verificamos que há evidência dessa associação para 1960 e 1980. No entanto, o padrão observado nos percentuais é claramente uma consequência da mudança na composição populacional, uma vez que o número de mulheres alcançando níveis educacionais mais elevados passou por uma completa revolução entre 1960 e 2000, e a associação estatística que acabamos de mencionar não é muito forte. Por exemplo, em 1960, apenas $0,2 \%$ das mulheres tinha alguma educação universitária, enquanto 1,4\% dos homens tinha alcançado esse nível educacional. Em 2000, esses percentuais passaram a ser 5,8\% para os homens e 6,3\% para as mulheres. Realmente houve uma explosão do acesso das mulheres ao sistema educacional.

Em resumo, os percentuais descritos nesta seção são o produto de dois tipos de força social: (1) composição populacional e (2) preferências individuais e/ou normas sociais. Como já vimos, se não houvesse associação estatística entre características de maridos e esposas, as taxas de homogamia e heterogamia descritas seriam significantemente diferentes. Mais especificamente, haveria muito mais heterogamia do que a descrita acima. Nesse sentido, é altamente relevante verificar os padrões de associação entre as características dos cônjuges não só para verificar em que medida eles determinam os padrões de casamento mas também para indicar qual é o papel que preferências individuais e/ ou normas sociais desempenham nesses padrões de casamento para além das tendências demográficas.

\section{SELETIVIDADE MARITAL POR COR DOS CÔNJUGES}

Os poucos estudos sobre seletividade marital por cor dos cônjuges no Brasil se dedicaram, por um lado, a analisar os padrões de casamento em apenas um ano ou analisar tendências usando coortes de idade (Silva, 1987; 1992); por outro, a apresentar taxas absolutas comparando os censos de 1960 e 1991 (Scalon, 1992; Telles, 2004). Nenhum trabalho analisou tendências de longo prazo nas chances relativas de casamento inter-racial. Neste artigo, dedicamo-nos a estimar essas tendências para o período que vai de 1960 a 2000. Além de apresentarmos e interpretarmos as taxas absolutas (ver a seção Taxas Absolutas de Seletividade Conjugal), procuramos estimar modelos que descrevam mudanças nas chances relativas de casamento inter-racial. Esse tipo de exercício é importante porque permite mensurar as chances relativas de ca- 
samento controlando pelo tamanho dos grupos que, como vimos anteriormente, determinam, em grande medida, os percentuais de casamentos homogâmicos e heterogâmicos. A análise das chances relativas de casamento, por sua vez, permite determinar o grau de fluidez social do mercado matrimonial. A Tabela 6 apresenta os modelos utilizados e os parâmetros obtidos pelo modelo preferido para analisar as tabelas de casamento cruzando raça do marido $(\mathrm{H})$ com raça da esposa $(\mathrm{W})$ e ano do censo ( $\mathrm{T})$.

Tabela 6

Modelos para Tabela Cruzando Cor do Marido (H) com Cor da Esposa (W) e Ano do Censo (T) para Casais em que Ambos os Cônjuges Tinham entre 20 e 34 anos em 1960, 1980 e 2000

\begin{tabular}{l|c|c|c|c}
\hline Modelo & L $^{2}$ & g.l. & Sig. & Bic \\
\hline 1. HT, WT & $13.112,9$ & 12 & 0,000 & $12.991,9$ \\
2. HT, WT, HW & 828 & 8 & 0,000 & 750 \\
$\begin{array}{l}\text { 3. HT, WT, HW (barreiras de cor } \\
\quad+\text { homogamia de pardos) }\end{array}$ & 837,6 & 9 & 0,000 & 745,9 \\
$\begin{array}{l}\text { 4. HT, WT, T * HW (barreiras de } \\
\quad \text { cor + homogamia de pardos) }\end{array}$ & 6,4 & 3 & 0,094 & $-23,8$ \\
\hline Parâmetros & & $\mathbf{1 9 6 0}$ & $\mathbf{1 9 8 0}$ & $\mathbf{2 0 0 0}$ \\
Branco/pardo & & $-1,69$ & $-1,26$ & $-0,59$ \\
Pardo/preto & & $-1,83$ & $-1,65$ & $-1,12$ \\
Homogamia entre pardos & & 0,90 & 0,53 & 0,84 \\
Chances relativas & & & & \\
Branco/pardo & & 0,19 & 0,28 & 0,55 \\
Pardo/preto & & 0,16 & 0,19 & 0,33 \\
Homogamia entre pardos & & 2,47 & 1,70 & 2,31 \\
\hline
\end{tabular}

Elaboração dos autores.

Inicialmente, ajustamos o modelo de independência (1: HT, WT), que pressupõe não haver associação estatística entre a cor de maridos e esposas e, portanto, que os casamentos inter-raciais são aleatórios. Como esperado, esse modelo não é estatisticamente significativo $\left(\mathrm{L}^{2}=\right.$ $13.112,9 ;$ g.l. = 12; Bic $=12.991,9$ ), o que indica que os casamentos inter-raciais não são aleatórios. Em seguida, ajustamos o modelo de associação constante no tempo (Modelo 2), que pressupõe que há associação entre cor de maridos e esposas, mas que ela não é a mesma entre 1960 e 2000. Embora o Modelo 2 não se ajuste aos dados $\left(L^{2}=828 ;\right.$ g.l. = 8 ; Bic $=750)$, a inclusão de um termo para explicar a relação entre cor de 
maridos e esposas explica $93,7 \%{ }^{5}$ da associação não explicada pelo modelo de independência (Modelo 1). No Modelo 3, propomos uma especificação mais parcimoniosa e substantivamente interessante para a associação entre cor de maridos e esposas. Ou seja, utilizamos um parâmetro para capturar a barreira ao casamento entre brancos e pardos, outro para definir a barreira separando pardos e pretos, e um último efeito para dar conta da propensão à endogamia entre pardos ${ }^{6}$. Os dois parâmetros de barreira ao casamento inter-racial também servem para estimar a endogamia para brancos e pretos. Usando um grau de liberdade a menos, o Modelo 3 é melhor do que o 2, embora ainda não se ajuste bem aos dados. Finalmente, o Modelo 4 considera a mudança temporal na associação entre cor de maridos e esposas, o que leva ao bom ajuste aos dados de acordo com a estatística $\mathrm{L}^{2}$ e o Bic $\left(\mathrm{L}^{2}=6,4 ; \mathrm{g}\right.$.l. $=3 ; \mathrm{Bic}=-23,8)$ - quanto mais negativa a estatística Bic, melhor o ajuste dos modelos aos dados. Vamos deixar a interpretação dos parâmetros estimados para a seção seguinte, mas vale adiantar que o Modelo 4, assim como o modelo preferido da próxima seção, indica que há um aumento significativo entre 1960 e 2000 na probabilidade de casamentos entre brancos e pardos, bem como na de casamentos entre pardos e pretos ou entre pretos e brancos. Em outras palavras, a propensão para casamentos inter-raciais está aumentando significativamente no Brasil, sendo mais acentuada para os casamentos entre brancos e pardos, e depois para aqueles entre pardos e pretos, tendo os casamentos entre brancos e pretos como os menos prováveis, embora essa propensão também tenha aumentado entre 1960 e 2000. Isso significa que os pardos estão mais próximos dos brancos do que dos pretos em termos de chances relativas de casamento e que todas as barreiras para casamentos inter-raciais tenham diminuído significativamente entre 1960 e 2000 .

Esse resultado é importante porque confirma as previsões de Silva (1992), mostrando que, em termos de casamentos, brancos e pardos estão mais próximos do que pardos e pretos, bem como que a propensão para casamentos inter-raciais estaria aumentando no Brasil. Observe-se que a proximidade entre brancos e pardos contrasta com outra encontrada em análises sobre desigualdades no mercado de trabalho e no sistema educacional, em que pretos e pardos estão, com frequência, muito próximos entre si e distantes dos brancos. Ou seja, no mercado matrimonial, em oposição ao mercado de trabalho e ao sistema educacional, os pardos têm mais chances de se casar com brancos do que com pretos. Teoricamente, esses resultados são importantes porque, ao to- 
marmos weberianamente o casamento como um indicador de sociabilidade ou contatos sociais entre diferentes grupos raciais (isto é, da distância social, diferente de distância socioeconômica, entre os grupos de cor), confirmamos a observação de que o Brasil se caracteriza por relações raciais cada vez mais fluidas, com forte favorecimento à miscigenação. Esses resultados contrastam com as análises sobre ascensão social em áreas mais duras, como mercado de trabalho e sistema educacional, nas quais as desvantagens de pretos e pardos se alteram de forma mais lenta ao longo das décadas (ver Ribeiro, 2008). No mercado matrimonial e, portanto, na esfera da sociabilidade e da proximidade mais íntima entre os grupos raciais, há um aumento rápido e significativo da fluidez, indicando crescente proximidade e aceitação entre os diferentes grupos de cor.

\section{SELETIVIDADE MARITAL POR EDUCAÇÃO}

Só temos conhecimento de um estudo sobre tendências de seletividade marital educacional no Brasil (Silva, 2003). Esse estudo utilizou um modelo de barreiras educacionais e mostrou que, entre 1981 e 1999, observavam-se as seguintes tendências: diminuição da barreira aos casamentos entre pessoas analfabetas e com primário ( 1 a 4 anos de estudo); diminuição da barreira separando aqueles com primário daqueles com secundário ( 5 a 8 anos de estudo); estabilidade da barreira separando os com secundário dos com colegial ( 9 a 11 anos de estudo); e aumento da barreira separando aqueles com colegial daqueles com alguma educação superior (12 ou mais anos de estudo). Esses resultados confirmam tendências encontradas em outros países (ver Mare, 1991). Nesta seção, apresentamos os resultados obtidos a partir de nossos dados. A Tabela 7 apresenta os diversos modelos ajustados à tabela cruzando educação do marido (E) com educação da esposa (S) e ano do censo $(\mathrm{T})$.

Como era esperado, o modelo de independência (Modelo 1) não se ajusta aos dados $\left(\mathrm{L}^{2}=12.783,3 ;\right.$ g.l. $\left.=48 ; \mathrm{Bic}=12.299,3\right)$. O modelo seguinte (2) inclui a associação entre educação do marido e da esposa, e assume que essa associação é constante entre 1960 e 2000. Embora apresente uma enorme melhora do ajuste em relação ao modelo anterior, ainda não é estatisticamente significativo $\left(L^{2}=493,0\right.$; g.l. = 32; Bic $=170,8$ ). Os Modelos de 3 a 5 testam diferentes especificações para a associação entre educação de maridos e esposas, mas, em todos os casos, assumem que a associação é constante ao longo do tempo. O Modelo 3 
Tabela 7

Modelos Ajustados à Tabela Cruzando Educação do Marido (E) com Educação da Esposa (S) e Ano do Censo (T) para Casais em que Ambos os Cônjuges Tinham entre 20 e 34 anos em 1960, 1980 e 2000

\begin{tabular}{|c|c|c|c|c|}
\hline Modelos & $\mathrm{L}^{2}$ & g.l. & Valor-p & Bic \\
\hline 1. ET, ST & $12.783,4$ & 48 & 0,000 & $12.299,3$ \\
\hline 2. ET, ST, ES & 493,0 & 32 & 0,000 & 170,8 \\
\hline 3. ET, ST, ES (simetria) & 512,5 & 38 & 0,000 & 129,2 \\
\hline 4. ET, ST, ES (barreiras educacionais) & 818,9 & 44 & 0,000 & 375,2 \\
\hline $\begin{array}{l}\text { 5. ET, ST, ES (barreiras educacionais + homoga- } \\
\text { mia nas categorias intermediárias) }\end{array}$ & 546,1 & 41 & 0,000 & 135,5 \\
\hline $\begin{array}{l}\text { 6. ET, ST, ES (homogamia nas categorias inter- } \\
\text { mediárias), ES (barreiras educacionais) } * \mathrm{~T}\end{array}$ & 76,4 & 33 & 0,000 & $-256,5$ \\
\hline $\begin{array}{l}\text { 7. ET, ST, ES (homogamia nas categorias inter- } \\
\text { mediárias) }{ }^{*} \mathrm{~T}, \mathrm{ES} \text { (barreiras educacionais) }{ }^{*} \mathrm{~T}\end{array}$ & 55 & 27 & 0,001 & $-216,4$ \\
\hline $\begin{array}{l}\text { 8. ET, ST, ES (homogamia nas categorias inter- } \\
\text { mediárias) + ES (barreiras educacionais) } * \mathrm{~T}+ \\
\text { (hipergamia/hipogamia) }{ }^{*} \mathrm{~T}\end{array}$ & 63 & 30 & 0,000 & -239 \\
\hline
\end{tabular}

Elaboração dos autores.

testa um padrão de simetria e homogamia na associação, ou seja, testa a hipótese de que os padrões de casamento de esposas são simétricos aos dos maridos e que há homogamia variável em cada nível educacional. Embora não se ajuste aos dados, o Modelo 3 indica que o padrão de simetria e homogamia, apesar de usar menos graus de liberdade, não é pior do que o de associação completa do Modelo 2. Esse teste é importante porque sugere que há simetria nos padrões de casamento de maridos e esposas. O Modelo 4 também não se ajusta aos dados, mas utiliza outro tipo de especificação da simetria, que é teoricamente mais interessante porque permite estimar barreiras ao casamento entre maridos e esposas com diferentes níveis educacionais. O Modelo 5, que acrescenta ao 4 o padrão de homogamia nas três categorias educacionais intermediárias, também não se ajusta. Os Modelos 3 e 5 são teoricamente equivalentes porque testam um padrão de simetria e homogamia nos casamentos, embora em ambos os casos esse padrão seja constante entre 1960 e 2000 . Finalmente, o Modelo 6 permite que o padrão de simetria estimado a partir das barreiras educacionais varie ao longo do tempo, mantendo o padrão de homogamia constante ao longo do tempo. Esse Modelo 6 é o primeiro a se ajustar bem aos dados de acordo com a estatística Bic $\left(\mathrm{L}^{2}=76,4 ; \mathrm{g} .1 .=48 ; \mathrm{Bic}=-256,5\right)$. O Modelo $7\left(\mathrm{~L}^{2}\right.$ $=55,0 ;$ g.l. $=27 ; \mathrm{Bic}=-216,4)$ acrescenta ao anterior a variação temporal 
da homogamia nas três categorias educacionais intermediárias, o que não melhora significativamente o ajuste e gasta mais graus de liberdade. Finalmente, o Modelo 8 acrescenta ao 6 um parâmetro para capturar uma possível assimetria representada pela maior chance de mulheres casarem com homens mais educados do que elas. Como vimos na análise das taxas absolutas, há uma mudança espetacular na expansão educacional das mulheres, o que se poderia traduzir em uma mudança na assimetria dos padrões de casamento em que homens tendiam a ter educação mais elevada do que a esposa.

Embora o Modelo 8 não se ajuste melhor do que o 6, que é o preferido para a análise desses dados, o parâmetro indicando que homens tendem a casar com mulheres menos educadas proposto no Modelo 8 fornece informação interessante. Ou seja, em 1960, os maridos tinham 1,3 vez mais chance de serem mais educados do que as esposas; em 1980, essa chance diminuiu para 1,1 vez mais; em 2000, não há assimetria educacional nas chances de casamento de maridos e esposas. Em outras palavras, em 2000, as chances de encontrarmos maridos mais educados do que suas esposas são aleatórias, ao passo que, nos anos anteriores, essas chances são mais sistemáticas, ou não aleatórias.

O Modelo 6, que, como já indicamos, é o preferido para esta análise, apresenta resultados interessantes sobre as mudanças nas barreiras educacionais aos casamentos no Brasil. Tendo em vista que as análises da próxima seção sobre a seletividade matrimonial por cor e educação dos cônjuges revelam que o padrão de barreiras educacionais não se modifica quando consideramos a cor dos cônjuges, deixaremos a interpretação desses parâmetros para a seção seguinte. Vale adiantar, no entanto, que as tendências são de diminuição das barreiras educacionais entre 1960 e 2000. De todo modo, as análises acima são importantes para determinar que modelo utilizar para a seletividade matrimonial por nível educacional dos cônjuges. Agora sabemos que, para a seletividade matrimonial por cor, podemos usar um padrão de associação tal como o especificado no Modelo 4 da seção anterior e que, para a seletividade por educação, devemos utilizar um padrão de associação tal como o definido no Modelo 6 desta seção (ambos representados na Equação 1 da quarta seção). Ao combinarmos esses dois modelos, testaremos se as barreiras ao casamento inter-racial se modificam quando levamos em conta as barreiras ao casamento intereducacional. Como mencionamos na introdução, é possível que os padrões de casamento inter-racial observados sejam, na realidade, um reflexo da diminuição 
das barreiras educacionais e da desigualdade educacional entre os grupos de cor.

\section{SELETIVIDADE MARITAL POR COR E EDUCAÇÃO}

Nesta seção, combinamos os modelos preferidos das duas seções anteriores em uma única análise, ou seja, aplicamos uma série de modelos à tabela cruzando cor do marido $(\mathrm{H})$ com cor da esposa (W), educação do marido (E), educação da esposa (S) e ano do censo (T). Essa tabela com cinco variáveis requer uma série de testes mais complexos do que os apresentados até agora. $\mathrm{O}$ aumento da complexidade na análise é importante na medida em que permite testar formalmente se as mudanças na seletividade matrimonial por educação dos cônjuges têm alguma influência sobre as mudanças nas chances de casamento entre grupos de cor e vice-versa. Esta pesquisa é a primeira a analisar conjuntamente os dois tipos de seletividade matrimonial no Brasil. A Tabela 8 apresenta as diferentes etapas de ajuste dos modelos aos dados. Procedemos por etapas, adicionando parâmetros em cada modelo subsequente.

Tabela 8

Ajuste de Modelos Log-Lineares à Tabela Cruzando Cor do Marido (H) com Cor da Esposa (W), Educação do Marido (E), Educação da Esposa (S) e Ano do Censo (T) para Casais em que Ambos os Cônjuges Tinham entre 20 e 34 Anos de Idade em 1960, 1980 e 2000

\begin{tabular}{l|c|c|c|c}
\hline Modelos & L $^{2}$ & g.l. & Valor-p & Bic \\
\hline 1. Modelo de base & & & & \\
H, W, E, S, T, HE, WS & 37.716 & 644 & 0,000 & 31.219 \\
2. Modelo 1 + HT, WT, ET, ST, HET, WST & 24.834 & 588 & 0,000 & 18.902 \\
3. Modelo 2 + ES (barreiras educacionais) & 13.240 & 584 & 0,000 & 7.349 \\
4. Modelo 3 + HW (barreiras de cor) & 2.022 & 582 & 0,000 & -3.849 \\
5. Modelo 4 + T * ES (barreiras educacionais) & 1.580 & 574 & 0,000 & -4.211 \\
6. Modelo 5 + T * HW (barreiras de cor) & 780 & 570 & 0,000 & -4.970 \\
7. Modelo 6 + ES (homogamia nas três cate- & & & & \\
$\quad$ gorias intermediárias) & $\mathbf{5 7 8}$ & $\mathbf{5 6 7}$ & $\mathbf{0 , 3 6 8}$ & $\mathbf{- 5 . 1 4 2}$ \\
8. Modelo 7 + HW (homogamia dos pardos) & 429 & 566 & 1,000 & -5.281 \\
9. Modelo 7 + T * ES (homogamia dos pardos) & 545 & 561 & 0,683 & -5.115 \\
\hline
\end{tabular}

Elaboração dos autores.

O primeiro modelo é o de independência entre cor e educação de maridos e esposas. Como era esperado, ele não se ajusta aos dados $\left(\mathrm{L}^{2}=\right.$ 37.716; g.l. $=644 ; \mathrm{Bic}=31.219)$. O segundo modelo controla pela varia- 
ção dos marginais da tabela ao longo do tempo, mas assume que não há associação entre as características de maridos e esposas. Como o anterior, esse modelo também não se ajusta bem aos dados. O Modelo 3 acrescenta ao 2 a associação entre educação de maridos e esposas segundo o padrão de barreiras educacionais, o que também não leva a um ajuste aceitável. Ao adicionarmos um parâmetro para as barreiras ao casamento inter-racial, obtemos o Modelo 4, que é o primeiro a se ajustar bem aos dados de acordo com a estatística Bic $\left(\mathrm{L}^{2}=2.022,4 ; \mathrm{g} .1\right.$. $=582 ; \mathrm{Bic}=-3.849)$. Esse modelo assume que a associação entre educação de maridos e esposas segue um padrão de barreiras educacionais; a associação entre cor de maridos e esposas também segue um padrão de duas barreiras de cor; e ambos os tipos de associação são constantes ao longo do tempo. Ao permitir que os parâmetros de barreiras educacionais variem ao longo do tempo, o Modelo 5 apresenta um ajuste ainda melhor do que o 4 aos dados $\left(\mathrm{L}^{2}=1.580\right.$; g.l. = 574; Bic = -4.211). No Modelo 6, acrescentamos a variação temporal aos parâmetros de barreiras de cor e alcançamos um melhor ajuste em relação aos modelos anteriores $\left(\mathrm{L}^{2}=780 ; \mathrm{g} .1 .=570 ; \mathrm{Bic}=-4.970\right)$.

Como vimos nas duas seções anteriores, alguns parâmetros de homogamia são necessários para explicar a associação entre as características de maridos e esposas. No Modelo 7, acrescentamos a homogamia para as três categorias educacionais intermediárias. Ao incluirmos esse parâmetro, obtemos um ajuste melhor do que o de todos os modelos anteriores em termos tanto da estatística Bic $(=-5.142)$ quanto da razão de verossimilhança $\left(\mathrm{L}^{2}=578\right.$; g.l. = 567; valor-p $\left.<0,368\right)$. No Modelo 8 , incluímos o parâmetro para a homogamia de pardos, o que leva a um ajuste excessivo do modelo aos dados (poderíamos dizer que o ajuste quase reproduz os dados, o que não é recomendável). Finalmente, o Modelo 9, adicionando ao 7 a variação temporal do parâmetro de homogamia educacional, não apresenta um melhor ajuste aos dados. Modelos testando a interação entre cor dos cônjuges e educação dos cônjuges também não apresentam melhora em relação ao Modelo 7, que permanece sendo o melhor para analisar esses dados.

De acordo com o Modelo 7, há variação temporal nas associações entre cor do marido e da esposa, e entre educação do marido e da esposa. Esses efeitos são aditivos, ou seja, um deve ser somado ao outro, mas não há interferência ou interação entre as propensões de casamentos intereducacionais e entre grupos de cor. Em outras palavras, ao controlarmos a associação entre cor de maridos e esposas pela associação en- 
tre educação de maridos e esposas, observamos que esses dois efeitos se somam, ou seja, eles não são reflexo um do outro. Substantivamente, isso significa que os padrões de seletividade matrimonial por cor e educação, analisados a partir dos modelos das seções anteriores, são válidos. A única diferença é que, ao incluirmos a homogamia educacional e a por cor no mesmo modelo, a segunda não é estatisticamente significativa. Além disso, a análise conjunta permite verificar não apenas em que medida um tipo de efeito se soma ao outro (cálculo que fazemos mais abaixo para interpretar os resultados) mas também qual barreira é mais difícil de ser transposta: a de cor ou a educacional. A Tabela 9 apresenta alguns parâmetros estimados pelo Modelo 7, bem como as chances relativas derivadas desses parâmetros (exponencial dos parâmetros). Barreiras educacionais de curta distância (entre grupos educacionais próximos) são mais fáceis de serem transpostas do que barreiras de cor, ao passo que barreiras educacionais de longa distância tendem a ser mais difíceis de serem transpostas do que barreiras de cor. A soma desses dois tipos de barreira, no entanto,

Tabela 9

Parâmetros Selecionados Estimados pelo Modelo 7, Casais com Ambos os Cônjuges com Idade entre 20 e 34 Anos

Brasil, 1960, 1980 e 2000

\begin{tabular}{l|c|c|c|c|c|c}
\hline \multirow{2}{*}{ Cor } & \multicolumn{3}{|c|}{ Parâmetros Estimados } & \multicolumn{3}{c}{ Chances Relativas } \\
\cline { 2 - 7 } & $\mathbf{1 9 6 0}$ & $\mathbf{1 9 8 0}$ & $\mathbf{2 0 0 0}$ & $\mathbf{1 9 6 0}$ & $\mathbf{1 9 8 0}$ & $\mathbf{2 0 0 0}$ \\
\cline { 2 - 7 } Branca/parda & & & & & \\
Parda/preta & $-2,005$ & $-1,433$ & $-0,889$ & 0,135 & 0,239 & 0,411 \\
Branca/preta & $-2,037$ & $-1,743$ & $-1,194$ & 0,130 & 0,175 & 0,303 \\
Educação & $-4,042$ & $-3,175$ & $-2,083$ & 0,018 & 0,042 & 0,125 \\
0-3 a 4-7 & & & & & & \\
4-7 a 8 & $-1,723$ & $-1,240$ & $-0,900$ & 0,178 & 0,289 & 0,407 \\
8 a 9-11 & $-1,450$ & $-1,058$ & $-0,787$ & 0,235 & 0,347 & 0,455 \\
9-11 a 12 ou mais & $-0,587$ & $-0,799$ & $-0,684$ & 0,556 & 0,450 & 0,505 \\
Homogamia educacional & $-0,915$ & $-1,089$ & $-1,126$ & 0,401 & 0,337 & 0,324 \\
4-7 & & & & & & \\
8 & $-0,620$ & $-0,620$ & $-0,620$ & 0,538 & 0,538 & 0,538 \\
9-11 & $0,040^{*}$ & $0,040^{*}$ & 0,040 & - & - & - \\
\hline
\end{tabular}

Elaboração dos autores.

Obs.: * Não significativo. 
revela algumas tendências interessantes, as quais descrevemos mais adiante.

Como especificamos anteriormente, o Modelo 7 inclui parâmetros para barreiras aos casamentos entre grupos de cor e entre pessoas com níveis educacionais distintos. Quanto menores essas barreiras, mais prováveis os casamentos inter-raciais e intereducacionais. Parâmetros com valores mais altos (menos negativos) correspondem a maiores chances relativas de cruzar as respectivas barreiras. Chances relativas menores (obtidas por parâmetros menores) indicam barreiras educacionais e de cor menos permeáveis ou, inversamente, mais rígidas. Todas as barreiras a casamentos entre grupos de cor se tornaram significativamente mais permeáveis entre 1960 e 2000. As chances de casamento entre brancos e pardos aumentaram de 0,135 em 1960 para 0,239 em 1980 e para 0,411 em 2000. Aumento semelhante ocorreu para o casamento entre pardos e pretos, passando de 0,130 em 1960 para 0,303 em 2000, e entre brancos e pretos, passando de 0,018 para 0,125 nessas mesmas datas. Outra maneira de entender esses números é calcular as chances de casamento dentro dos mesmos grupos de cor (homogâmicos). Por exemplo, mantendo-se a educação constante, podemos dizer que, em 1960, uma pessoa preta tinha 56 vezes (ou 1/0,018) mais chances de se casar com outra pessoa igualmente preta do que de se casar com uma pessoa de outra cor, ao passo que quarenta anos mais tarde, em 2000, essas chances haviam diminuído para apenas oito vezes. De forma semelhante, uma pessoa branca tinha sete vezes mais chances de se casar com outra pessoa branca do que com uma pessoa de outra cor em 1960 e apenas duas vezes mais em 2000. Em suma, as barreiras aos casamentos inter-raciais estão se tornando cada vez menos rígidas ou, inversamente, a sociedade brasileira está se tornando significativamente mais aberta ou fluida em termos de casamento entre grupos de cor. É bom lembrar, no entanto, que essas chances que acabamos de mencionar assumem que o nível educacional se mantém constante, ou seja, que não há variação nos níveis educacionais. Mais adiante apresentamos informações sobre chances de casamento entre pessoas com cor e educação distintas, mas antes é importante apresentarmos as mudanças nas barreiras educacionais também obtidas pelo Modelo 7 .

As mudanças nas barreiras educacionais entre 1960 e 2000 seguem um padrão um pouco diferente do das mudanças nas barreiras aos casamentos inter-raciais. Enquanto as barreiras separando grupos educacionais mais baixos diminuíram, aquelas separando pessoas com se- 
gundo grau (9 a 11 anos de educação) de pessoas com alguma educação universitária (12 anos ou mais) aumentaram. A Tabela 8 também apresenta essas tendências. As chances de cruzar barreiras separando pessoas com 0 e 3 anos de estudo de outras com 4 e 7 anos passaram de 0,18 em 1960 para 0,41 em 2000. Uma tendência semelhante ocorreu na barreira separando pessoas tendo entre 4 e 7 anos de estudo daquelas com primário completo ( 8 anos de educação), ou seja, a permeabilidade aumentou de 0,23 em 1960 para 0,46 em 2000. Já a barreira separando pessoas com primário completo ( 8 anos) daquelas com algum secundário (9 a 11 anos) diminuiu em menor proporção, passando de 0,56 em 1960 para 0,50 em 2000.

Em contraste com esse aumento de permeabilidade nas três barreiras educacionais mais baixas, a barreira separando pessoas com alguma educação de segundo grau (9 a 11 anos) de pessoas com alguma educação universitária (12 anos ou mais) se tornou ligeiramente mais rígida ou menos permeável. A permeabilidade dessa barreira diminuiu de 0,40 em 1960 para 0,32 em 2000. Inversamente, podemos dizer que a homogamia entre pessoas com algum nível universitário aumentou. Em 1960, as chances de casamento homogâmico para pessoas com alguma educação universitária eram 2,5 vezes maior do que as chances de casamento educacionalmente heterogâmico, ao passo que em 2000 essas chances aumentaram para 3,1 vezes mais. Mais uma vez devemos tomar cuidado ao interpretar esses números, porque eles assumem que não há variação na barreira separando grupos de cor, que, como vimos, está na realidade diminuindo. Uma maneira mais realista de interpretar esses números é observar alguns tipos de combinação entre barreiras aos casamentos entre pessoas com níveis educacionais distintos e em diferentes combinações de cor dos cônjuges. Fazemos esses cálculos a seguir.

Uma das propriedades do Modelo 7 é que os parâmetros para cada uma das quatro barreiras educacionais podem não apenas ser somados entre si, para obtermos estimadores de chances relativas de casamento cruzando mais de uma barreira, mas também somados às chances de cruzar barreiras ao casamento entre grupos de cor. Aproveitando essa característica do modelo, calculamos, na Tabela 10, as chances relativas de cônjuges cruzarem uma, duas, três ou quatro barreiras educacionais para os três tipos de casamento inter-racial. Apresentamos apenas valores para o triângulo inferior porque o modelo é simétrico, ou seja, o valor para os casamentos entre maridos mais educados 
do que esposas é exatamente o mesmo que para o caso inverso, em que esposas são mais educadas. Podemos, assim, interpretar as linhas ou colunas como sendo a especificação do nível educacional de esposas ou de maridos.

As barreiras educacionais são cumulativas, portanto cruzar uma é mais fácil do que cruzar duas e assim por diante. Casamentos cruzando quatro barreiras educacionais (entre pessoas com educação entre $0 \mathrm{e}$ 3 anos e pessoas com 12 ou mais anos de escolaridade) são extremamente raros, independentemente da cor dos cônjuges. Isso indica que, para casamentos entre pessoas com nível socioeconômico (medido pela educação) muito diferente, praticamente não há efeito das barreiras de cor, ou seja, nesses casos, é realmente a barreira educacional que impede casamentos de qualquer tipo. Para casamentos cruzando uma, duas ou três barreiras educacionais, o efeito das barreiras de cor parece ser mais relevante. De fato, as barreiras educacionais são crescentemente mais rígidas (o valor numérico diminui cada vez mais) na seguinte ordem por tipo de casamento entre grupos de cor: entre brancos e pardos; entre pardos e pretos; e entre brancos e pretos. Além disso, há uma tendência de aumento das chances de cruzar barreiras educacionais entre 1960 e 2000 (o valor numérico é cada vez maior), ou seja, todas as barreiras educacionais e de cor se tornam mais permeáveis ao longo dos quarenta anos estudados. Mesmo assim, as chances de cruzar quatro barreiras educacionais ainda permanecem muitíssimo baixas para casamentos entre pessoas de todas as cores.

As tendências gerais de mudanças nas barreiras educacionais ao casamento para cada combinação de grupo de cor já foram descritas no parágrafo anterior, mas a descrição de alguns exemplos pode ajudar a ilustrar os resultados. Em 1960, as chances de casamento entre pessoas tendo 8 anos de escolaridade e pessoas tendo entre 0 e 3 anos eram de: 0,006 para casamentos entre brancos e pardos; 0,005 para casamentos entre pardos e pretos; e 0,001 para casamentos entre brancos e pretos. Em 2000, essas chances aumentaram para: 0,076 para casamentos entre brancos e pardos; 0,056 para casamentos entre pardos e pretos; e 0,023 para casamentos entre brancos e pretos. Várias outras mudanças seguindo o mesmo padrão podem ser observadas nos valores das chances relativas apresentadas na Tabela 10 .

Outra maneira de observar os dados da Tabela 10 é apresentada a seguir, nos Gráficos 1, 2 e 3. Essas representações gráficas apenas reorde- 
Cor, Educação e Casamento: Tendências da Seletividade Marital...

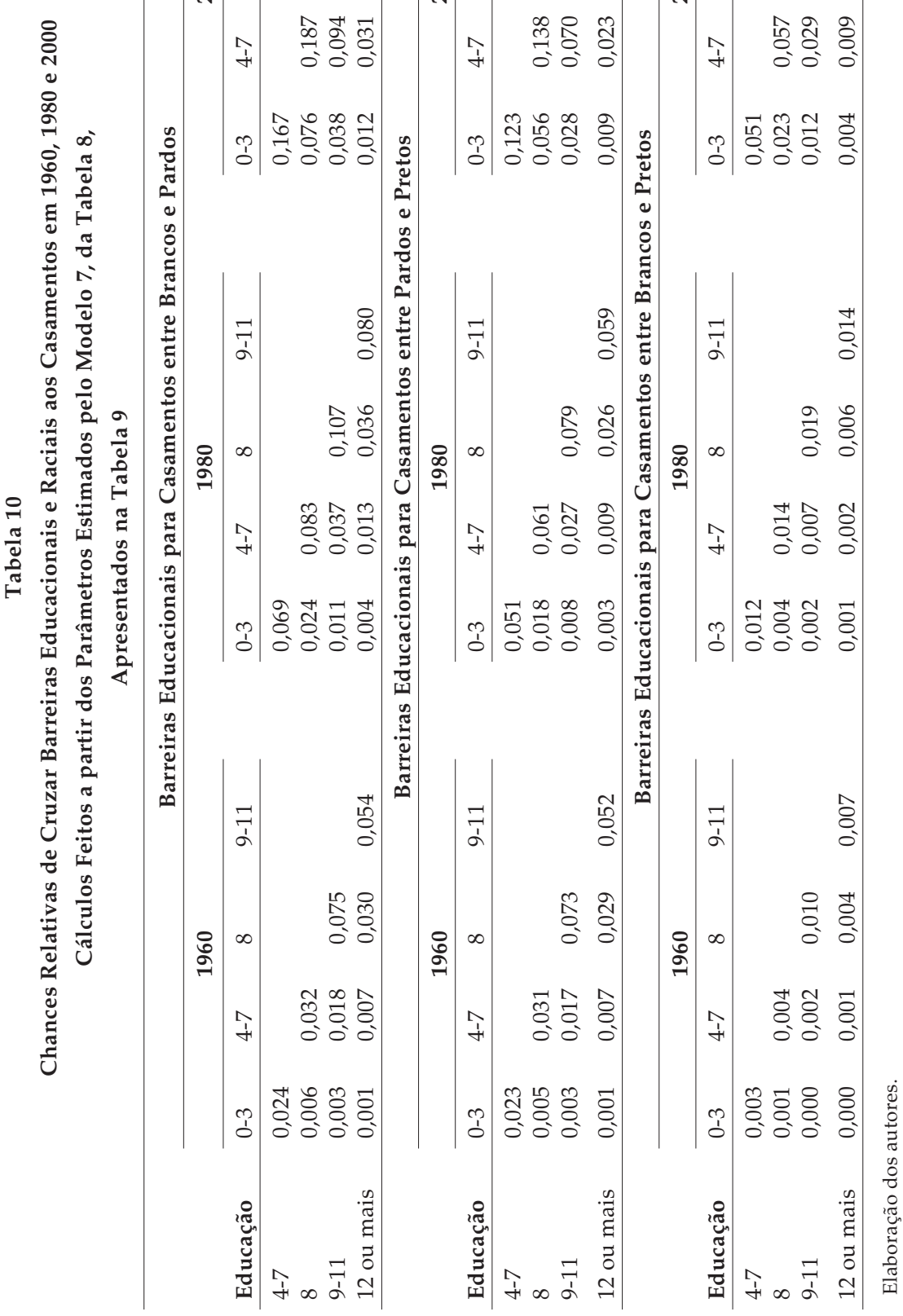




\section{Gráfico 1}

Barreiras Educacionais para cada Tipo de Casamento Inter-Racial

(Brasil, 1960)

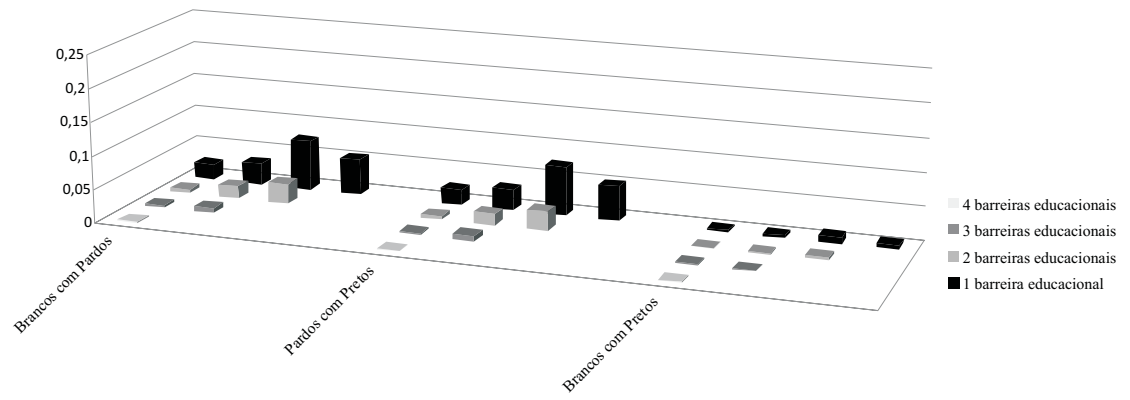

Gráfico 2

Barreiras Educacionais para cada Tipo de Casamento Inter-Racial

(Brasil, 1980)

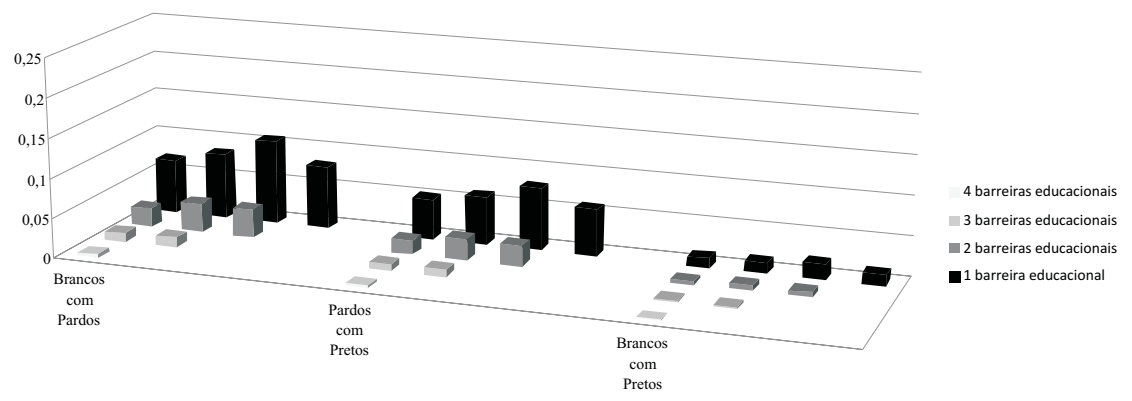

Gráfico 3

Barreiras Educacionais para cada Tipo de Casamento Inter-Racial

(Brasil, 2000)

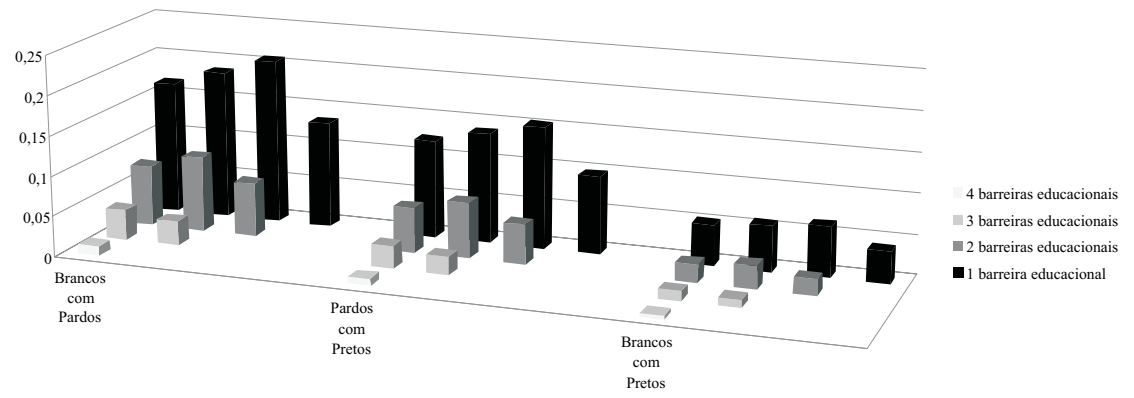


nam os números da Tabela 10 a fim de facilitar a visualização das tendências. Os gráficos mostram as chances de cruzar uma, duas, três e quatro barreiras educacionais para casamentos inter-raciais em 1960, 1980 e 2000. As colunas para uma barreira educacional estão ordenadas da esquerda para a direita: 0-3 anos de escola para 4-7 anos; 4-7 anos para 8 anos; 8 anos para 9-11 anos; e 9-11 anos para 12 anos ou mais. As colunas para duas barreiras educacionais também estão ordenadas da esquerda para a direita: $0-3$ anos para 8 anos de escola; 4-7 anos para 9-11 anos; e 8 anos para 12 anos ou mais. Da mesma forma, as colunas para três barreiras educacionais: 0-3 anos para 9-11 anos; e 4-7 anos para 12 anos ou mais. Finalmente, a coluna para quatro barreiras educacionais representa chances de casamento entre pessoas com 0-3 anos de escolaridade e com 12 anos ou mais.

As tendências expressas nos Gráficos 1, 2 e 3 são bastante claras. A primeira informação relevante e válida para todos os anos é que as chances de casamento entre brancos e pardos são um pouco maiores do que as entre pardos e pretos, e ambas são muito maiores do que as entre brancos e pretos. Como previsto na literatura, os pardos ocupam uma posição intermediária entre brancos e pretos, estando um pouco mais próximos dos brancos, e as chances de todos os tipos de casamento inter-racial aumentam entre 1960 e 2000. Além disso, podemos dizer que: (1) as chances de casamento cruzando uma e duas barreiras educacionais aumentam para todos os tipos de casamento inter-racial entre 1960 e 2000; (2) as chances de casamento cruzando três barreiras educacionais eram muito pequenas em 1960, mas também apresentam tendência de aumento ao longo dos anos para todos os tipos de casamento inter-racial; e (3) as chances de casamento cruzando quatro barreiras educacionais são muito pequenas para qualquer tipo de casamento inter-racial. De fato, há evidências de que as chances de casamento cruzando quatro barreiras educacionais são extremamente baixas, o que expressa claramente a desigualdade socioeconômica existente no Brasil. Ou seja, pessoas com 12 anos ou mais de escolaridade estão muito distantes em termos socioeconômicos de pessoas com educação entre 0 e 3 anos. Casamentos cruzando quatro barreiras são, portanto, raríssimos, independentemente da cor dos cônjuges.

\section{CONCLUSÃO}

Em suma, podemos concluir que, entre 1960 e 2000, houve uma diminuição realmente significativa nas barreiras, dificultando o casamento 
entre pessoas brancas, pardas e pretas, bem como entre pessoas com níveis educacionais diferentes. Isso significa que a sociedade brasileira parece estar se tornando significativamente mais aberta aos casamentos cruzando barreiras educacionais e de cor. Isso não quer dizer, no entanto, que as barreiras de cor e educacionais não existam, mas indica uma forte tendência de diminuição dessas barreiras. Interpretando os casamentos como um indicador da proximidade entre os grupos de cor, podemos concluir que, pelo menos na esfera da sociabilidade representada pela união matrimonial, há uma crescente tendência de aceitação de pessoas de grupos de cor distintos, sendo a proximidade de brancos e pardos significativamente maior do que a de pardos e pretos. Essas tendências são independentes do nível educacional dos cônjuges, ou seja, não são apenas um reflexo da diminuição das desigualdades educacionais entre brancos, pardos e pretos nem da crescente diminuição das barreiras educacionais aos casamentos. Essas últimas barreiras, por sua vez, também estão diminuindo, o que indica que casamentos entre pessoas com níveis educacionais distintos são cada vez mais comuns.

As barreiras entre grupos educacionais adjacentes diminuíram significativamente entre 1960 e 2000, com exceção da barreira aos casamentos entre pessoas com segundo grau (9-11 anos) e universidade (12 anos ou mais), a qual está se tornando mais rígida, sobretudo por causa do aumento do número de mulheres alcançando educação universitária entre 1960 e 2000. Ou seja, como as mulheres passaram a frequentar em números cada vez maiores as universidades entre 1960 e 2000, a tendência aos casamentos entre homens e mulheres com algum nível universitário aumentou muito: a endogamia nesse grupo educacional cresceu significativamente. Além disso, é importante ressaltar que as barreiras aos casamentos entre pessoas com níveis educacionais muito distintos continuam extremamente fortes, o que torna esse tipo de casamento muito improvável, independentemente da cor dos cônjuges. De fato, as barreiras ao casamento entre pessoas com níveis educacionais muito diferentes são muito mais fortes do que as barreiras aos casamentos inter-raciais.

(Recebido para publicação em novembro de 2008) (Versão definitiva em março de 2009) 


\section{NOTAS}

1. Esses percentuais incluem apenas as populações branca e afro-americana para os Estados Unidos em 1998, e as branca e não branca (parda e preta) para o Brasil em 2000 .

2. Não é possível fazer uma explicação pormenorizada desses modelos por falta de espaço neste artigo, mas os leitores interessados podem encontrar as especificações em Powers e Xie (2000:107-119).

3. Como a inclusão de apenas um termo de ordem superior (segunda ordem, por exemplo), em qualquer modelo, implica a inclusão de todos os termos de ordem inferior (primeira ordem, por exemplo), não faremos referência aos termos de ordem inferior na Tabela 8.

4. Esses percentuais foram calculados a partir do modelo de independência estatística entre a cor dos cônjuges. Como veremos adiante, esse modelo não se ajusta aos dados.

5. Esse percentual é calculado da seguinte forma: ( $\mathrm{L}^{2}$ modelo $\mathrm{A} 1-\mathrm{L}^{2}$ modelo $\left.\mathrm{A} 2\right) /\left(\mathrm{L}^{2}\right.$ modelo A1).

6. Na tabela com três linhas para categorias de cor de maridos e três colunas para categorias de cor de esposas, diversas especificações desse mesmo modelo utilizando três graus de liberdade podem ser estimadas. Também estimamos uma alternativa com um parâmetro para cada homogamia por cor que é completamente equivalente ao modelo que apresentamos. 


\section{REFERÊNCIAS BIBLIOGRÁFICAS}

AZEVEDO, Thales de. (1955), As Elites de Cor: um Estudo de Ascensão Social. São Paulo, Companhia Editora Nacional.

. (1963), "Mestiçagem e 'Status' no Brasil". Actas do V Coloquio Internacional de Estudos Luso-Brasileiros. Coimbra, pp. 87-112.

. (1966), Cultura e Situação Racial no Brasil. Rio de Janeiro, Civilização Brasileira.

. (1975), Democracia Racial, Ideologia e Realidade. Petrópolis, Vozes.

BECKER, Gary S. (1981), A Treatise on the Family. Cambridge, Harvard University Press.

BELTRÃO, Kaizô I. e TEIXEIRA, Moema de Poli. (2005), “Cor e Gênero na Seletividade das Carreiras Universitárias", in S. B. Soares et alii (orgs.), Os Mecanismos de Discriminação Racial nas Escolas Brasileiras. Brasília, IPEA.

BLAU, Peter M., BLUM, Terry C. e SCHWARTZ, Joseph. (1982), "Heterogeneity and Intermarriage". American Sociological Review, vol. 47, pp. 45-62.

BLAU, Peter M. e SCHWARTZ, Joseph. (1984), Crosscutting Social Circles. London, Academic Press.

BLOSSFELD, Hans-Peter e TIMM, Andreas. (2003), Who Marries Whom? Educational Systems as Marriage Markets in Modern Societies. Netherlands, Kluwer Academic Publishers.

BOZON, Michel e HÉRAN, François. (1989). “Finding a Spouse: Survey of How French Couples Meet". Population, vol. 44, no 1, pp. 91-121.

BUMPASS, Larry. (1970), "The Trend of Interfaith Marriage in the United States". Social Biology, vol. 17, no 4, pp. 253-259.

DAVIS, Kingsley. (1984), “Wives and Work: Consequences of Sex-role Revolution”. Population and Development Review, vol. 10, no 3, pp. 397-417.

DIMAGGIO, Paul e MOHR, John. (1985), "Cultural Capital, Educational Attainment, and Marital Selection". American Journal of Sociology, vol. 90, no 6, pp. 1231-1261.

FORSÉ, Michel e CHAUVEL, Louis. (1995). “L'Évolution de l'Homogamie en France: Une Méthode pour Comparer les Diagonalités de Plusieurs Tables". Revue Française de Sociologie, vol. 36, no 1, pp. 123-142.

GULLICKSON, Aaron. (2006), "Education and Black-White Interracial Marriage". Demography, vol. 43, no 4, pp. 673-689.

HOUT, Michael. (1983), Mobility Tables. Beverly Hills, Sage.

JACOBS, Jerry A. e FURSTENBERG JR., Frank F. (1986), “Changing Places, Conjugal Careers, and Women's Marital Mobility". Social Force, vol. 64, no 3, pp. 714-762.

JOHNSON, Robert A. (1980), Religious Assortative Marriage in the United States. New York, Academic Press.

KALMIJN, Matthijs. (1991a), "Shifting Boundaries: Trends in Religious and Educational Homogamy". American Sociological Review, vol. 56, pp. 786-800.

. (1991b), "Status Homogamy in the United States". American Journal of Sociology, vol. 97, no 3, pp. 497-523. 
(1994), "Assortative Mating by Cultural and Economic Occupational Status". American Journal of Sociology, vol. 100, no 2, pp. 422-452.

. (1998). "Intermarriage and Homogamy: Cause, Patterns, Trends". Annual Review of Sociology, vol. 24, pp. 395-421.

MARE, Robert D. (1991), "Five Decades of Educational Assortative Mating". American Sociological Review, vol. 56, no 1, pp. 15-32.

MERTON, Robert K. (1941), "Intermarriage and the Social Structure: Fact and Theory". Psychiatry, vol. 4, no 36, pp. 361-374.

MURSTEIN, Bernard. (1976), Who Will Marry Whom? Theories and Research in Marital Choice. New York, Springer.

PIERSON, Donald. (1942), Negroes in Brazil: A Study of Race Contact at Bahia. Chicago, University of Chicago Press.

POWERS, Daniel e XIE, Yu. (2000), Statistical Methods for Categorical Data Analysis. New York, Academic Press.

QIAN, Zhenchao. (1997), “Breaking the Racial Barriers: Variations in Interracial Marriage Between 1980 and 1990". Demography, vol. 34, no 2, pp. 263-276.

RAYMO, James M. e XIE, Yu. (2000), “Temporal and Regional Variation in the Strength of Educational Homogamy". American Sociological Review, vol. 65, no 5, pp. 773-781.

RIBEIRO, Carlos Antonio Costa. (2008), Inequality of Educational Opportunity in Brazil: Race, Class and Gender. Mimeo.

SCALON, Maria Celi. (1992), Cor e Seletividade Conjugal no Brasil. Dissertação de mestrado em Sociologia, IUPERJ, Rio de Janeiro.

SCHWARTZ, Christine R. e MARE, Robert D. (2005), “Trends in Educational Assortative Marriage from 1940 to 2003". Demography, vol. 42, no 4, pp. 621-646.

SILVA, Nelson do Valle. (1987), "Distância Social e Casamento Inter-Racial no Brasil". Estudos Afro-Asiáticos, vol. 14, pp. 54-83.

. (1992), “Estabilidade Temporal e Diferenças Regionais no Casamento Inter-Racial no Brasil", in C. Hasenbalg e N. do V. Silva (orgs.), Relações Raciais no Brasil. Rio de Janeiro, Rio Fundo Editora.

. (2003), "Duas Décadas de Seletividade Marital Educacional no Brasil", in C. Hasenbalg e N. do V. Silva (orgs.), Origens e Destinos: Desigualdades Sociais ao Longo da Vida. Rio de Janeiro, Topbooks.

SMITS, Jeroen, ULTEE, Wout e LAMMERS, Jan. (1998), “Educational Homogamy in 65 Countries: An Explanation of Differences in Openness Using Country-Level Explanatory Variables". American Sociological Review, vol. 63, no 2, pp. 264-285.

STALEY, Austin John. (1959), Racial Democracy in Marriage: A Sociological Analysis of Negro-White Intermarriage in Brazilian Culture. Tese de doutorado, University of Pittsburgh, Pittsburgh.

TELLES, Edward E. (2004), Race in Another America: The Significance of Skin Color in Brazil. Princeton, Princeton University Press.

WEBER, Max. (1978), Economy and Society. Berkeley, University of California Press.

WILLEMS, Emílio. (1961), Uma Vila Brasileira: Tradição e Transição. São Paulo, Difel. 


\section{ABSTRACT \\ Color, Education, and Marriage: Trends in Marital Selectiveness in Brazil from 1960 to 2000}

The article analyzes trends in marital selectiveness among blacks, browns, and whites in Brazil, using data from 1960, 1980, and 2000. Given that the educational system expanded and racial inequalities decreased over the years, the article aims to investigate to what extent these trends are related to the reduction in barriers to interracial marriage, as observed during the period. The authors thus analyze marriage patterns in couples of different color and schooling. The reduction in barriers to interracial marriage is independent of the parallel decrease in couples with different educational levels. Such barriers have become less common in all groups, except for those with the most education; in other words, the odds of marriage between husbands and wives with any level of university education increased from 1960 to 2000, corresponding to an increase in the barrier to marriage between highly educated individuals and less educated partners. Nevertheless, the overall trend was towards a decrease in barriers to interracial and inter-educational marriages from 1960 to 2000. In other words, there are steadily fewer impediments to interracial and inter-educational marriages in Brazil.

Key words: marital selectiveness; race relations; education

\section{RÉSUMÉ \\ Couleur de Peau, Éducation et Mariage: Tendances de la Sélection Maritale au Brésil de 1960 à 2000}

Dans cet article, on analyse les tendances de la sélection maritale entre noirs, mulâtres et blancs au Brésil, à partir de données couvrant les années 1960, 1980 et 2000. En considérant que le système d'éducation s'est développé et que les inégalités raciales ont diminué avec les années, on cherche à savoir dans quelle mesure ces tendances sont liées à l'aténuation des barrières aux mariages inter-raciaux observée dans la période en question. Dans ce sens, on examine les modèles de mariage entre personnes de couleur de peau et niveau scolaire différents. La diminution des barrières dans le mariage inter-racial ne dépend pas de la diminution parallèle des mariages de niveau scolaire différent. Ces derniers diminuent chez tous les groupes, sauf pour les plus scolarisés, c'est-à-dire que les chances de mariage entre hommes et femmes de scolarité 
supérieure sont plus grandes entre 1960 et 2000, ce qui correspond à un accroissement de la barrière pour les mariages entre gens très scolarisés et peu scolarisés. Malgré cela, la tendance générale est de diminution des barrières aux mariages inter-raciaux et entre des gens de niveau-scolaire différent entre 1960 et 2000. Soit, il y a de moins en moins de restrictions aux mariages inter-raciaux et entre des gens de niveau scolaire différent au Brésil.

Mots-clé: sélection matrimoniale; relations raciales; éducation 